\title{
Development of amyloid beta gold nanorod aggregates as optoacoustic
}

\section{probes}

Mahmoud G Soliman ${ }^{\mathrm{a}, \mathrm{b}}$, Hannah A Davies ${ }^{\mathrm{a}}$, Jack Sharkeyc ${ }^{\mathrm{c}}$, Raphaël Lévy ${ }^{\mathrm{d}}$, Jillian Madine ${ }^{\mathrm{a}, *}$

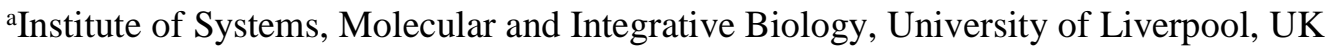

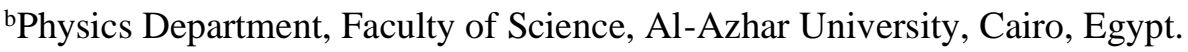

${ }^{\mathrm{c} C e n t r e ~ f o r ~ P r e-C l i n i c a l ~ I m a g i n g, ~ U n i v e r s i t y ~ o f ~ L i v e r p o o l, ~ U K ~}$

${ }^{\mathrm{d} C h e m i s t r y, ~ S t r u c t u r e s, ~ P r o p e r t i e s ~ o f ~ B i o m a t e r i a l s ~ a n d ~ T h e r a p e u t i c ~ A g e n t s, ~ U n i v e r s i t e ́ ~ S o r b o n n e ~ P a r i s ~}$ Nord and UMR CNRS 7244, France

*Corresponding author: j.madine@ liverpool.ac.uk 


\section{Abstract}

Propagation of small amyloid beta (A $\beta$ ) aggregates (or seeds) has been suggested as a potential mechanism of Alzheimer's disease progression. Monitoring the propagation of A $\beta$ seeds in an organism would enable testing of this hypothesis and, if confirmed, provide mechanistic insights. This requires a contrast agent for long-term tracking of the seeds. Gold nanorods combine several attractive features for this challenging task, in particular, their strong absorbance in the infrared (enabling optoacoustic imaging) and the availability of several established protocols for surface functionalization. In this work, polymer-coated gold nanorods were conjugated with anti-A $\beta$ antibodies and specifically attached to pre-formed $A \beta$ seeds. The resulting complexes were characterized for their optical properties by UV/Vis spectroscopy and multispectral optoacoustic tomography. The complexes retained their biophysical properties, i.e. their ability to seed $A \beta$ fibril formation. They remained stable in biological media for at least 2 days and showed no toxicity to SH-SY5Y neuroblastoma cells up to $1.5 \mathrm{nM}$ and $6 \mu \mathrm{M}$ of gold nanorods and $A \beta$ seeds, respectively. Taken together, this study describes the first steps in the development of probes for monitoring the spread of $A \beta$ seeds in animal models. 


\section{Introduction}

Aggregation and deposition of $A \beta$ and tau proteins occurs in the brain in Alzheimer's disease and is linked to neurodegeneration [1]. However, the trigger for $A \beta$ and tau deposition remains unknown. Recent research has highlighted pathological similarities between amyloid and prion diseases [2-4]. In prion disease, the mis-folded protein acts as a template or 'seed' to convert the native protein to a misfolded pathogenic form. Growing evidence suggests that a similar 'seeding' mechanism could be associated with additional amyloid disorders such as Alzheimer's disease [3], Parkinson's disease [5], Huntington's disease [6], AA amyloidosis [7] and ATTR amyloidosis [8].

The body of evidence supporting $A \beta$ having prion-like properties and $A \beta$-associated diseases spreading via seeding is rapidly expanding. Early work showed that injection of Alzheimer's disease brain homogenates into young APP23 mice overexpressing amyloid precursor protein (APP) results in accelerated disease pathology observed by the presence of $A \beta$ plaques at an earlier age than control animals $[4,9]$. Whilst in the initial work, seeds were injected directly into the brain, a further study has shown that peripheral injection of seeds into the peritoneal cavity can also accelerate disease onset [10]. Support for a similar seeding mechanism in human patients was reported from post-mortem analysis of a cohort of patients that had received growth hormone injections, derived from cadavers, as children. A sub-set of this cohort developed Creuzt-Feldt Jacob disease (CJD), a well-known prion disease, as a result of growth hormone contamination with prion seeds. In 2015, Jaunmuktane, et al., reported that 4/8 patients also had signs of $A \beta$ deposition consistent with early onset of Alzheimer's disease and suggested that these patients could have contracted Alzheimer's disease in a similar mechanism to CJD, i.e. a prion-like infection with Alzheimer's disease seeds from cadaveric tissue [11], although those results are debated [12-14].

Evidence for the transmission of amyloid proteins is not confined to neurodegenerative diseases. Several groups have demonstrated the transmissibility of AA amyloidosis through a variety of administration routes and across species [15-17]. Furthermore there are suggestions that seeding mechanisms play a role in the development and progression of ATTR amyloidosis which affect 
treatment and prognosis [8]. In all these diseases and examples, a critical currently unknown factor is how seed species trigger disease, specifically how seed species injected at one site (e.g. peritoneal cavity of mice) can affect amyloid deposition elsewhere in the body (e.g. brain). To investigate this puzzling phenomenon, novel experimental approaches to track seed species from site of injection to site of action are needed. This would result in enhanced understanding of the mechanisms that underpin disease initiation and progression. As a first step towards this ambitious goal, we present in this article the preparation of seeds labelled with gold nanorods for future tracking with multispectral optoacoustic tomography (MSOT).

MSOT is a real-time optical imaging technique that provides a non-ionizing and noninvasive imaging modality which relies on the photoacoustic effect, which was first observed by Alexander G Bell in 1880 [18]. MSOT has been used for several preclinical and clinical applications [19-21] because of its high spatial resolution $(\sim 150 \mu \mathrm{m})$ and penetration depth $(\sim 5 \mathrm{~cm})$ [22]. In optoacoustic tomography, a short near infrared laser pulse is partially absorbed by endogenous molecules or exogenous contrast agents causing a rapid thermoelastic expansion, which generates ultrasound waves. These are detected by ultrasonic transducers placed outside the tissue [23]. MSOT relies on a multiwavelength excitation and subsequent spectral deconvolution to identify endogenous molecules or exogenous contrast agents [22]. Therefore, agents with strong and distinctive absorption spectra in the near infrared are best suited for MSOT imaging.

Gold nanoparticles have strong optical absorption that results from the surface plasmon resonance. The position of the absorption band can be tuned through changes in nanoparticle size and shape. Anisotropic nanoparticles, e.g., gold nanorods, exhibit two bands, the transverse plasmon band located in the visible region around $520 \mathrm{~nm}$, and the longitudinal band located in the near infra-red region, with the exact wavelength tunable by controlling the aspect ratio of the nanorods [24]. For this reason, gold nanorods have been successfully used as contrast agents for MSOT [25, 26]. In this work, we cross-link anti-A $\beta$ antibodies to gold nanorods and demonstrate that those conjugates selectively associate with A $\beta$ seeds. The resulting seeds-Abs-GNR complexes can serve as optical probes for MSOT imaging to monitor the propagation of $\mathrm{A} \beta$ seeds in in vivo murine models. 


\section{Materials and Methods}

\section{Materials}

Prior to use, all glassware was washed with aqua regia and rinsed thoroughly with milli-Q water. All chemicals were used as received. Hydrogen tetrachloroaurate (III) hydrate $\left(\mathrm{HAuCl}_{4}\right)$, hexadecyltrimethylammonium bromide (CTAB), sodium borohydride $\left(\mathrm{NaBH}_{4}\right)$, ascorbic acid, Ethyl3-(3-dimethylaminopropyl)carbodiimide $\quad$ (EDC)/N-hydroxysulfo-succinimide (sulfo-NHS), 2-(Nmorpholino)ethanesulfonic acid (MES), poly(isobutylene-maleic-altanhydride), hydrochloridric acid, 5-bromosalicylic acid, silver nitrate $\left(\mathrm{AgNO}_{3}\right)$, phosphine buffered saline (PBS), Ethylenediaminetetraacetic acid (EDTA), resazurin, and dodecylamine, $\alpha$-metoxy- $\omega$-thiolpoly(ethylene glycol) (mPEG-SH $\left.\left(\mathrm{PEG}_{2 \mathrm{k}}\right), \mathrm{Mw}=2 \mathrm{kDa}\right)$ HAMS-F12, Non-essential amino acids (NEAA), Penicillin-Streptomycin (Pen-Strep), mouse serum and Foetal Bovine Serum (FBS) were purchased from Sigma-Aldrich (UK). All cell culture plasticware was purchased from Corning Inc. (Corning, NY, USA).

\section{Synthesis of gold nanorods}

Gold nanorods with core diameter and length of ca.15 and $60 \mathrm{~nm}$, respectively, were prepared by the seed-mediated growth method by two steps (seed and growth solutions) as reported previously [27] Briefly, seed solution of less than $4 \mathrm{~nm}$ gold nanoparticles was prepared by mixing $5 \mathrm{~mL}$ of 0.5 $\mathrm{mMHAuCl}_{4}$ with $5 \mathrm{~mL}$ of $0.2 \mathrm{M} \mathrm{CTAB}$ in a glass vial. To this solution, $0.6 \mathrm{~mL}$ of freshly prepared $\mathrm{NaBH}_{4}$ diluted to $1 \mathrm{~mL}$ with deionized water was added with strong stirring for $2 \mathrm{~min}$. The resulted brown-yellow color solution was kept at room temperature for $15 \mathrm{~min}$ before use. To prepare a growth solution, $9.0 \mathrm{~g}$ of CTAB and $1.1 \mathrm{~g}$ of 5-bromosalicylic acid were dissolved in $250 \mathrm{~mL}$ of warm water in a $500 \mathrm{~mL}$ Erlenmeyer flask. After that, the solution was cooled down to $30{ }^{\circ} \mathrm{C}$, and $18 \mathrm{~mL}$ of 4 mMAgNO 3 was added. The mixture was kept at $30^{\circ} \mathrm{C}$ for $15 \mathrm{~min}$ and then, $250 \mathrm{~mL}$ of $1 \mathrm{mM} \mathrm{HAuCl}_{4}$ solution was added. After $15 \mathrm{~min}$ of stirring (400 rpm), $2 \mathrm{~mL}$ of $0.064 \mathrm{M}$ of ascorbic acid was added, and the solution was vigorously stirred for $30 \mathrm{~s}$ until it became colourless. Finally, $0.4 \mathrm{~mL}$ of freshly prepared seed solution (as described above) was injected into the growth solution and stirred for $30 \mathrm{~s}$. 
Finally, the solution was kept overnight at $30{ }^{\circ} \mathrm{C}$ without stirring to allow the gold nanorods to grow. Next day, the resulted gold nanorods were subjected to one-time cleaning by centrifugation (8960xg, $30 \mathrm{~min})$. Thereafter, the supernatant was discarded and the pellet was dispersed in deionized water and stored for further use.

\section{Phase transfer and polymer coating}

For polymer coating of gold nanorods, the aqueous solution was first subjected to a phase transfer from aqueous medium to organic solvent following the protocol previously reported [28] Briefly, a specific amount of $\mathrm{PEG}_{2 \mathrm{k}}$ in water (see Table S1) was injected into the solution of gold nanorods and further stirred at room temperature for $24 \mathrm{~h}$. After that, a $0.4 \mathrm{M}$ solution of dodecylamine in chloroform was added and the mixture stirred at $1200 \mathrm{rpm}$ until the gold nanorods was transferred to the chloroform phase. For purification, the particles were centrifuged twice (see Table S1 for parameters) to remove unbound/unreacted dodecylamine and $\mathrm{PEG}_{2 \mathrm{k}}$. Then, the gold nanorods were dispersed in chloroform and stored for further use. Their concentration was calculated using Beer Lambert law $\left(\mathrm{A}_{450}=\mathrm{c}_{\mathrm{NP}}\right.$. $\left.\varepsilon(450 \mathrm{~nm}) \cdot 1_{\text {path }}\right)$ with UV/Vis absorbance determined at wavelength of $450 \mathrm{~nm}\left(\mathrm{~A}_{450}\right)$ and extinction coefficient $\left(\varepsilon(450 \mathrm{~nm})=2.11 \cdot 10^{9}\left[\mathrm{M}^{-1} \mathrm{~cm}^{-1}\right]\right)$ as reported for gold nanorods of very similar dimensions [29]. Measurements were carried out with a cuvette path length of $1_{\text {path }}=1 \mathrm{~cm}$.

The dodecylamine-capped gold nanorods were transferred from chloroform to water by applying polymer coating technique using dodecyl-grafted-poly(isobutylene-alt-maleic anhydride)(in the following referred to as PMA) as described by Lin et al.[30]. For details about the synthesis of the amphiphilic polymer used here we refer to previous work [30]. The amount of added PMA per NP was calculated as described in the Supporting Information (appendix). The polymer coating was then carried out according to the protocol previously described [28]. A schematic illustration describes the steps of NPs' surface modification (Scheme 1). 


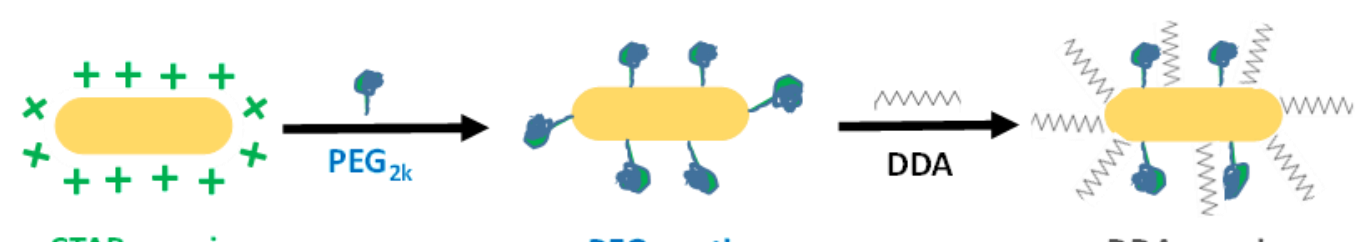

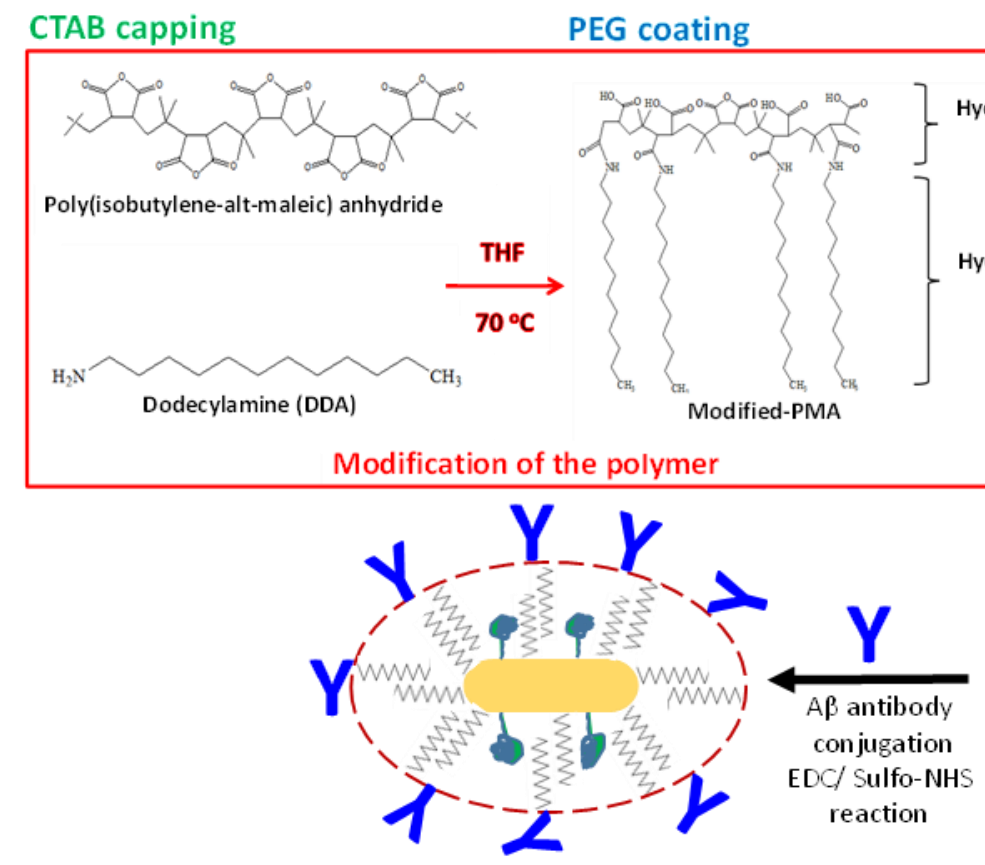

Antibody capping
DDA capping
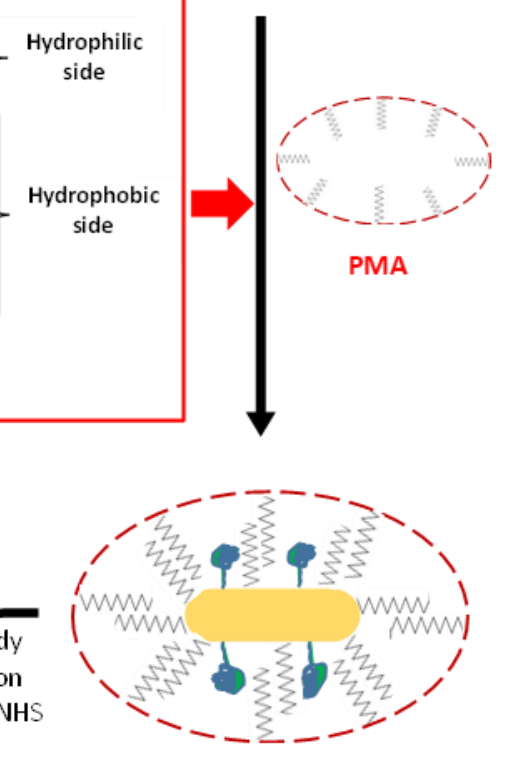

PMA capping

Scheme 1: Schematic illustration shows the steps of NPs' surface modification.

\section{Gold nanorods functionalization with antibodies}

After the polymer coating with PMA, the gold nanorods' surface is rich in carboxylic groups $(-\mathrm{COOH})$ that can be linked to $\mathrm{A} \beta$ antibodies (Abs-A $\beta$ ) using EDC/sulfo-NHS coupling reaction (Scheme 1)[31]. To achieve high conjugation efficiency, the concentrations of coupling reagents (EDC/Sulfo-NHS) and Abs-A $\beta$ were optimized sequentially. The molar ratio between EDC and sulfo-NHS was fixed at 1:2, and the amount of Abs- $\mathrm{A} \beta$ added to the reaction was introduced with the same volume as described in the following coupling reaction. Briefly, $10 \mu \mathrm{L}$ of Abs-A $\beta(5-75 \mu \mathrm{g} / \mathrm{mL}, 6 \mathrm{E} 10$ BioLegend) was added to a suspension of gold nanorods at a concentration of $5 \mathrm{nM}$ in $10 \mathrm{mM}$ MES buffer at $\mathrm{pH}$. To this mixture, an equal volume of a solution containing 0.5-4 mmoles of sulfo-NHS and 1-8 mmoles of EDC was added (see Table S2 for more details). The reaction mixture was left at room temperature for $2 \mathrm{~h}$ and then was incubated for extra $6 \mathrm{~h}$ at $4{ }^{\circ} \mathrm{C}$. 


\section{Association of gold nanorods with A $\mathbf{\beta 4 0}$}

A $\beta 40$ (BioLegend) was incubated in PBS at $200 \mu \mathrm{M}$ with agitation for 3 days at $37^{\circ} \mathrm{C}$. To produce seeds, $A \beta$ fibrils were subjected to three cycles of ultrasonication pulses (amplitude of $10 \%$ ) for a period of $30 \mathrm{sec} / \mathrm{cycle}$. A $\beta$ fibrils/seeds were diluted to required concentrations (0.1-10 $\mu \mathrm{M}$ equivalent monomer concentration) and incubated with gold nanorods (5-500 $\mathrm{pM})$ overnight at room temperature before using. The resulted complex ( $\mathrm{A} \beta$ fibrils or $\mathrm{A} \beta$ seeds-GNRs) were characterized by UV/Vis spectroscopy and transmission electron microscope (TEM).

\section{Physicochemical characterization}

Absorption spectra of gold nanorods with different surface coatings were acquired across the wavelength range of 400-1000 nm with UV/Vis spectrometer (Cary Eclipse).

A Malvern zetasizer Nano ZS was used to measure the hydrodynamic diameter $\left(\mathrm{d}_{\mathrm{h}}\right)$ and zeta potential $(\zeta$-potential) of the gold nanorods in water with dynamic light scattering and laser Doppler anemometry respectively. The latter was also used to characterize the $\zeta$-potentials of the prepared A $\beta$-seeds. All samples were equilibrated for $5 \mathrm{~min}$ at $25{ }^{\circ} \mathrm{C}$ to ensure motion was due to Brownian motion and not due to any thermal gradients. The data was acquired at $173^{\circ}$ backscatter settings, using a $633 \mathrm{~nm}$ laser. The determined $d_{h}[\mathrm{~nm}]$ and $\zeta$-potentials $[\mathrm{mV}]$ are summarized in Table S3. Each reported value was the average of at least three independent measurements.

Gold nanorods were also characterized at each step of surface modification using a CPS disc centrifuge DC24000 (CPS Instruments Inc.). For this purpose, a gradient fluid, 8-24 wt $\%$ sucrose solution in MilliQ water, was freshly prepared and injected in consecutive steps into the disc, rotating at a speed of $22000 \mathrm{rpm}$. Calibration was performed using poly(vinyl chloride) particles (PVC, $0.377 \mu \mathrm{m}$, Analytik Ltd.) as calibration standard before each measurement. Following PVC measurement, $100 \mu \mathrm{L}$ of gold nanorods solution was injected and analyzed three times to verify data reproducibility.

The dimensions of gold nanorods, their surface modification and their interaction with A $\beta$ species were investigated by TEM (Tecnai G3 spirit). The samples were prepared by deposition of a drop ( $5 \mu \mathrm{L})$ of 
diluted solution on a carbon coated copper grid and left to dry at room temperature. For negative staining samples, a drop of gold nanorods solution (incubated with A $\beta$-fibrils/seeds) was placed on a carboncoated copper grid for $2 \mathrm{~min}$. Following blotting, $5 \mu \mathrm{L}$ of $4 \%$ uranyl acetate was added for $30 \mathrm{sec}$. Size distributions were determined using ImageJ. At least 100 particles were considered to determine the average size of the different cores.

Gel electrophoresis experiments were conducted using $1 \%$ agarose gel prepared in tris-EDTA buffer at $\mathrm{pH}$ 7.4. Gold nanorod solutions were mixed with a specific volume of a negatively charged orange $\mathrm{G}$ as a gel-loading buffer to increase the density of the sample, following the protocol reported by Soliman et al. [28] and then loaded in the gel wells. Samples were run under an electric field of $100 \mathrm{~V}$ in trisEDTA buffer at room temperature for $1 \mathrm{~h}$ using a Bio-Rad horizontal electrophoresis system.

\section{Gold nanorods effect on protein aggregation}

Thioflavin T (ThT) fluorescence assay was used to assess fibril formation using a FlexStation3 MultiMode Microplate Reader (Molecular Devices). $10 \mu \mathrm{M}$ A 340 with $2 \mu \mathrm{M}$ of ThT was incubated in PBS at $37^{\circ} \mathrm{C}$ in a 96 well clear bottom/black wall 96 well plate. The measurements were made at regular intervals (every 5 minutes with shaking for $5 \mathrm{~s}$ before each read) with excitation and emission at 440 $\mathrm{nm}$ and $480 \mathrm{~nm}$, respectively. To stop the depletion of $\mathrm{A} \beta 40$ from the solution resulting from nonspecific binding, the plates were pre-coated with polyethylene glycol [32]. Briefly, $300 \mu \mathrm{L}$ of $0.01 \mathrm{M}$ polyethylene glycol $(\mathrm{Mw}=300 \mathrm{~g} / \mathrm{mol})$ was added into every well of the 96 -well plates and incubated at room temperature for 60 minutes. The wells were then aspirated completely and rinsed with 10 times their volume ( $3 \mathrm{ml})$ of Millipore ultra-pure water. The plates were allowed to dry at room temperature before use.

\section{Cell viability}

Cell viability was tested against SH-SY5Y neuroblastoma cells at cell density of 10,000 cells/well in a 96 well plate. The cells were incubated with the particles/A $\beta$ proteins for $24 \mathrm{~h}$ and their viability was evaluated by a standard resazurin assay [33]. Resazurin is a blue, non-fluorescent sodium salt, which is converted to Resorufin by metabolically active cells. Fluorescence spectra were recorded using 
FlexStation3 Multi-Mode Microplate Reader with excitation wavelength of $560 \mathrm{~nm}$. In all tested particles/proteins, the molarity and mass concentrations are indicated. Gold nanorods molar and mass concentrations were determined based on the UV/Vis absorbance values as described in supporting information (Appendix). Viability data are presented as percentage compared to untreated cells. Data was analysed statistically using analysis of variance and Tukey's post hoc test with $\mathrm{p}<0.05$.

\section{Optoacoustic imaging}

MSOT imaging was performed in the MSOT inVision 256-TF small animal imaging system (iThera Medical, Munich, Germany). For this purpose, an agar phantom was prepared by mixing $4 \mathrm{~g}$ of agar in $100 \mathrm{~mL}$ of hot water. Thereafter, the solution was placed in $50 \mathrm{~mL}$ tubes and stored at $4{ }^{\circ} \mathrm{C}$ for further use. To prepare, gold nanorods containing phantoms, different concentrations of $100 \mu \mathrm{L}$ of gold nanorods solution was placed in phantoms wells and five cross sections of the phantom were analyzed using 15 different wavelengths in the range from 660 to $950 \mathrm{~nm}$. The phantom was scanned in $2 \mathrm{~mm}$ steps and the following wavelengths used for acquisition; $680,720,760,800,810,820,830,840,850$, 860, 870, 880, 890, 900, $950 \mathrm{~nm}$. A linear based reconstruction method was applied using ViewMSOT software (iThera Medical, Munich, Germany). For multispectral images, the signal for the GNRs was unmixed by multispectral processing using the absorbance spectra for the GNRs

\section{Results and discussion}

\section{Gold nanorods synthesis}

Gold nanorods were prepared by a well-established procedure that results in particles capped with the toxic cationic surfactant $\mathrm{CTAB}$ [27]. To remove the bound $\mathrm{CTAB}$, the gold nanorods were transferred from water to chloroform using both $\mathrm{PEG}_{2 \mathrm{k}}$ and dodecylamine. Gold nanorods exhibit characteristic absorbance peaks in both the visible and near IR regions. The positions of those peaks are sensitive to the size end geometry of the particle, but also to its local environment refractive index. Thus, a $40 \mathrm{~nm}$ red shift of the longitudinal plasmon band was observed (from $830 \mathrm{~nm}$ to $870 \mathrm{~nm}$ ) due to the change in the refractive index of the dispersion medium from water to chloroform as shown in Fig 1a. Coating 
with an amphiphilic polymer (PMA-GNRs) was then used to transfer the particles back from chloroform to water and to serve as a platform for immobilization of antibodies using water-soluble cross-linkers EDC and sulfo-NHS [30]. The spectrum after transfer is similar to the starting material with a small blue shift of the peak. A range of experimental conditions were tested to maximize coupling yield estimated by the red shift of the plasmon band (Table S2 and Fig S1); in the optimized conditions a $\sim 5$ $\mathrm{nm}$ red shift is observed (Fig 1b, inset)[34]. In the absence of EDC/sulfo-NHS no change in localized surface plasmon resonance (LSPR) was detected consistent with no binding occurring (Fig S1a). Electron microscopy and dynamic light scattering confirm that the particles have a narrow size distribution that is preserved during the various modification steps, with a final increase of hydrodynamic diameter upon coupling of the A $\beta$ antibody (Fig S2 and S3, Table S3). Consistent with previous work $[35,36]$, the conjugation results in a reduction in the apparent diameter measured by CPS due to reduction in overall density upon antibody binding (Fig S4). Coupling of the A $\beta$ antibody to the PMA-coated gold nanorods was further confirmed by reduced electrophoretic mobility (Fig 1c) and changes in zeta potential (Fig S5, Table S3).
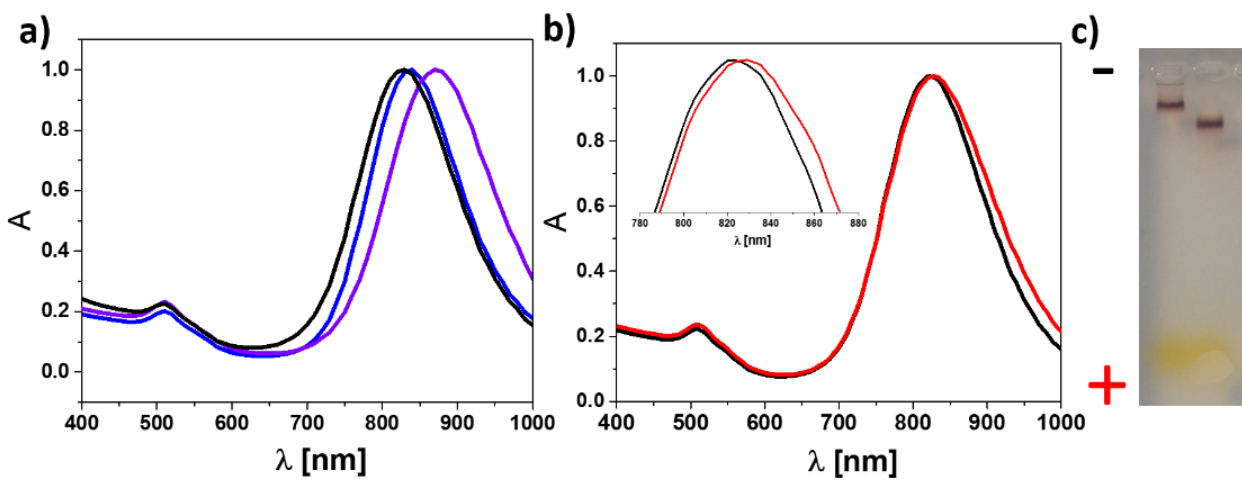

Fig 1. Conjugation of A $\beta$ antibody to gold nanorods. a) Normalized absorption spectra for CTABcapped gold nanorods (in water, blue), dodecylamine-capped gold nanorods (in chloroform, violet) and PMA-coated gold nanorods (in water, black). b) Normalized absorption spectra for gold nanorods after PMA coating (black) and after conjugation with A $\beta$ antibody (red). Inset shows normalized data for the LSPR shift of the gold nanorods after conjugation with antibody. c) Gel electrophoresis of gold nanorods before (right lane, PMA-GNRs) and after (left lane, AbsGNRs) conjugation with $A \beta$ antibody. 


\section{Abs-GNRs interact specifically with A $\beta-40$}

The interaction of PMA-GNRs and Abs-GNRs with $A \beta$ was investigated by analysing changes in the gold nanorods absorbance spectra in the presence of $\mathrm{A} \beta$ seeds and fibrils. No changes in the longitudinal plasmon band were observed when PMA-GNRs were incubated with A $\beta$ seeds or fibrils (Fig 2a, 2c). In contrast, with Abs-GNRs the spectra indicated a progressive reduction in intensity indicative of association with the seeds and fibrils formation (Fig 2b, 2d). As the Fig insets show, the position of the plasmon band maxima do not shift significantly. This absence of plasmon coupling indicates that the gold nanorods remain separated from each other within the fibrillar networks [37]. This may be explained by two main factors: 1) the large steric barrier between the nanorod cores provided by the PMA and antibody layers; 2) the nanorods do not bind directly to each other but instead to another extended object, i.e. the seeds or fibrils. The preserved shape of the spectrum is an important advantage for future MSOT detection as this technique relies on multispectral unmixing to distinguish contrast agents from endogenous absorbers. Specific association of Abs-GNRs with A $\beta 40$ is confirmed by TEM where Abs-GNRs are almost entirely co-localized with $A \beta$ seeds and fibrils, whereas under the same conditions, a large proportion of PMA-GNRs are observed randomly scattered over the grid (Fig 3). In the representative images shown in Fig 3, 95\% of Abs-GNRs colocalize with seeds compared with only 18\% of PMA-GNRs. Additional images are shown in Fig S5. Incubation of Abs-GNRS overnight with seeds from a different amyloidogenic protein medin confirmed that the association between $A \beta$ GNRs and $A \beta$ is specific (Fig S7). 

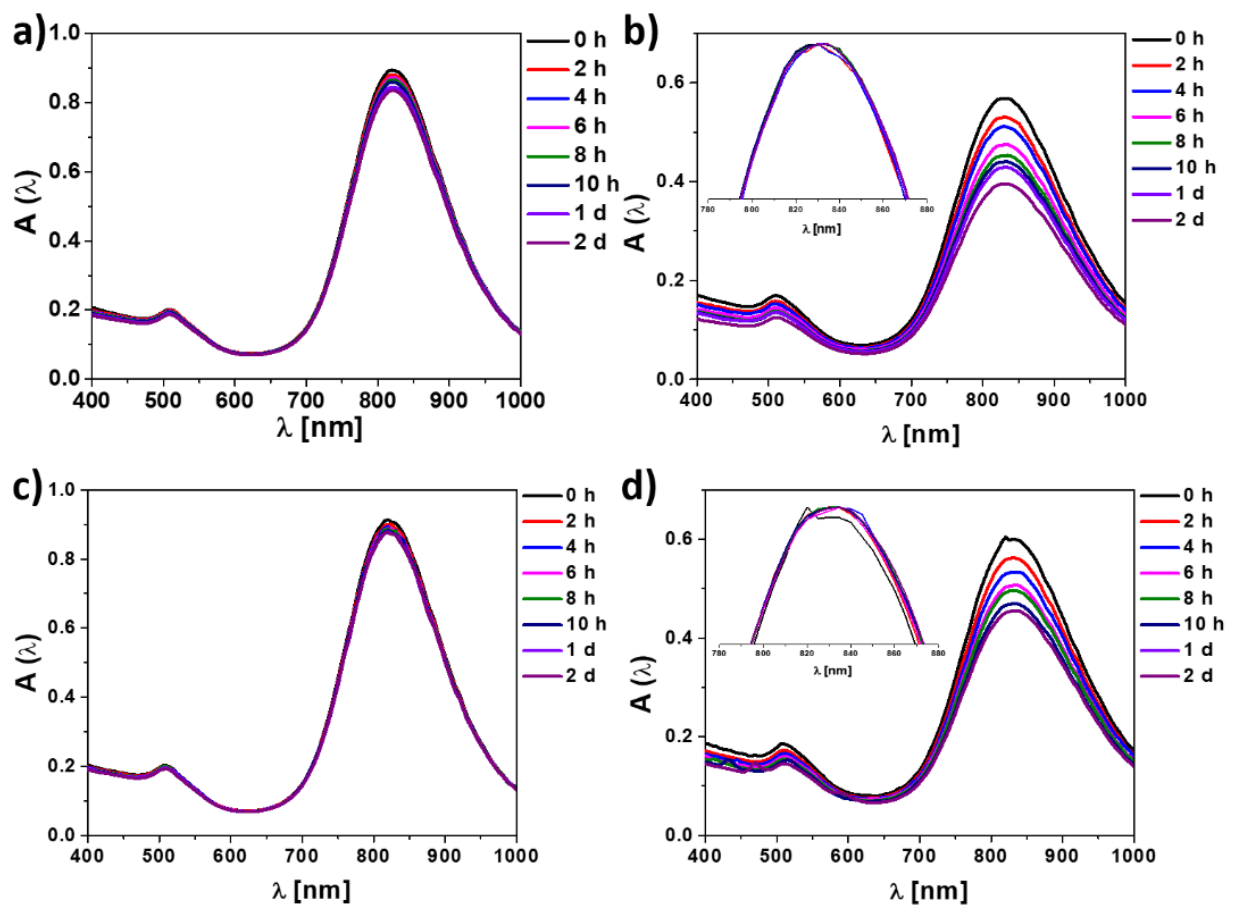

Fig 2. Abs-GNR show specific association with Aß-40 fibrils and seeds. Absorption spectra (not normalized) of a) PMA-GNRs with A $\beta$-seeds, b) Abs-GNRs with A $\beta$-seeds, c) PMA-GNRs with A $\beta$ fibrils, and d) Abs-GNRs with A $\beta$ fibrils in water at different time-points as shown. Loss of intensity is observed due to conjugation with insoluble $A \beta$ seeds and fibrils. Insets show normalized spectra. 


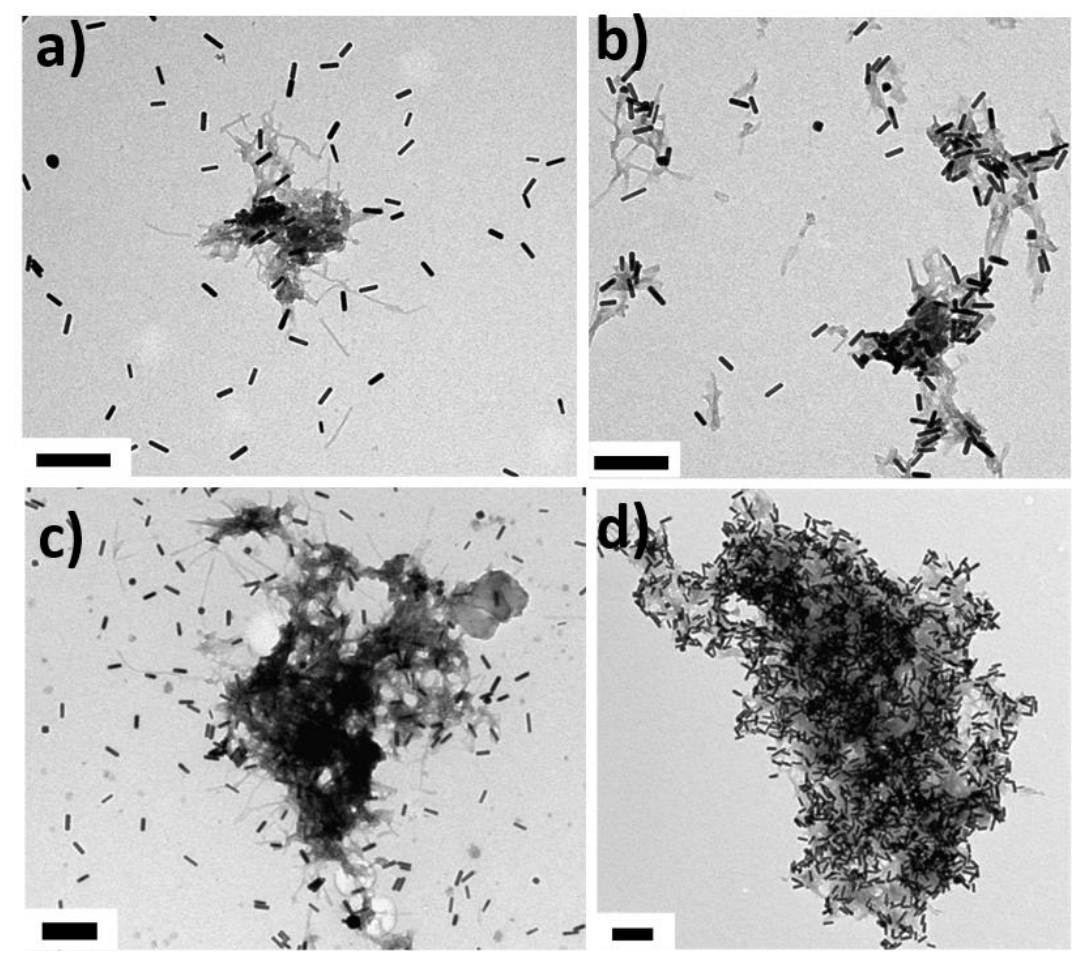

Fig 3. Electron microscopy confirms specific association of Abs-GNRs with A $\beta$ seeds and fibrils. A $\beta$ seeds incubated overnight with a) PMA-GNRs and b) Abs-GNRs. A $\beta$ fibrils incubated overnight with PMA-GNRs c) and Abs-GNRs d). Scale bars correspond to $200 \mathrm{~nm}$.

\section{Seeds-Abs-GNR complexes are stable and non-toxic}

Seeds-Abs-GNR complexes show stability assessed by absorption spectra in mouse serum, water and cell media up to 2 days (Fig 4a and Fig S8). To test viability, SH-SY5Y cells were exposed to PMAGNRs, Abs-GNRs, seeds-Abs-GNRs and A $\beta$ seeds for $24 \mathrm{~h}$ with viability assessed using the resazurin assay (Fig $4 \mathrm{~b}$ ). Results show that the presence of $1.5 \mathrm{nM}$ and $6 \mu \mathrm{M}$ of seeds-Abs-GNRs (Fig $4 \mathrm{~b}$, orange) can be employed in the developed optical probe with no significant effect on cell viability. These results are in good agreement with previous studies on toxicity of gold nanorods [28, 38] and $A \beta$ [39]. 

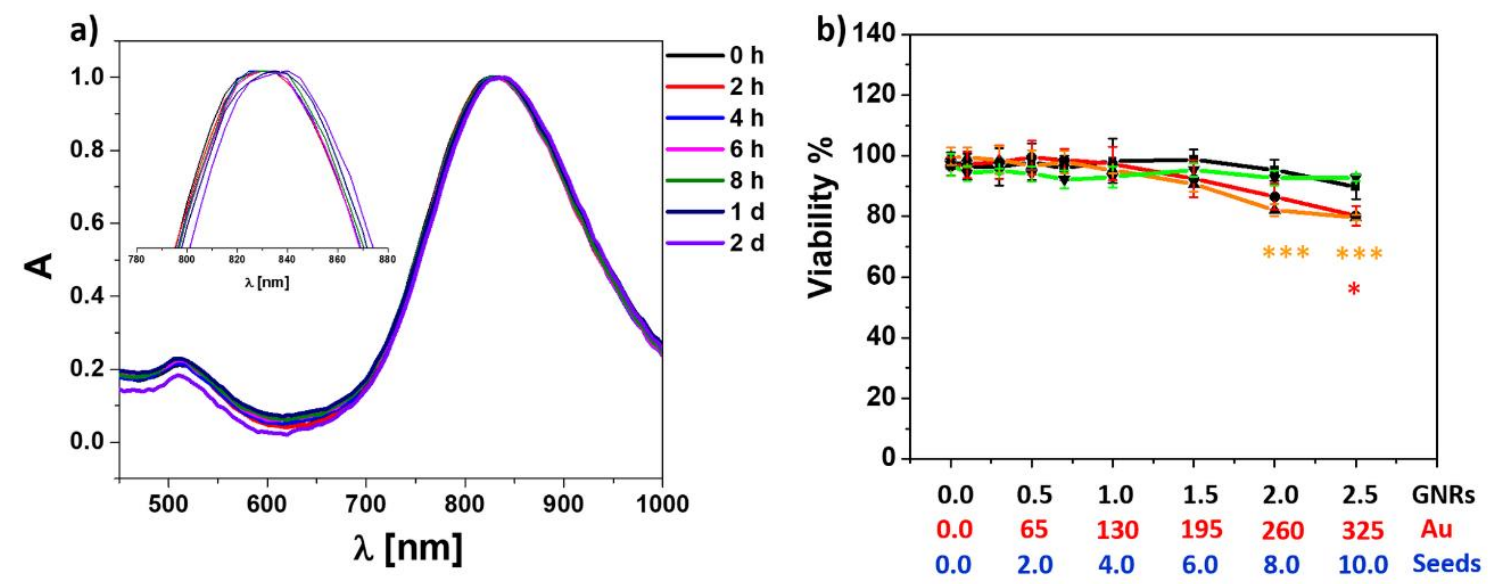

Fig 4. Gold nanorod complexes show stability and no toxicity under physiological conditions. (a) Normalized absorption spectra for pre-formed seeds-A $\beta$-GNRs in mouse serum at different time points (up to $2 \mathrm{~d}$ ). (b) Cellular viability (\%) as determined by the resazurin assay with SHSY5Y cells exposed to PMA-GNRs (black), Abs-GNRs (red), seeds-Abs-GNRs (orange) and Aß-seeds alone (green) for $24 \mathrm{~h}$ at the indicated concentrations of gold nanorods $(\mathrm{nM})$, gold $(\mu \mathrm{g} / \mathrm{mL})$ and A $\beta$ seeds $(\mu \mathrm{M})$. Data presented as mean \pm SD from 3 wells per condition and analysed statistically using analysis of variance and Tukey's post hoc test with $\mathbf{p}<0.05$. ${ }^{*} \mathbf{p}<0.05$, ***p $<0.0001$ compared to cells alone with colour corresponding to condition tested.

\section{Seeds-Abs-GNR-complexes retain seeding ability and can be}

\section{integrated into fibrillar networks}

The formation of $A \beta 40$ fibrils is nucleation-dependent and addition of pre-formed $A \beta 40$ seeds results in a concentration-dependent reduction in lag time (Fig 5a). Addition of seeds-Abs-GNR complexes shows a similar concentration-dependent reduction in lag time confirming they have retained the ability to seed A 340 fibrillation (Fig 5b). Addition of PMA-GNRs had no effect on fibril formation (Fig S9) consistent with lack of association between PMA-GNRs and A $\beta 40$. Addition of Abs-GNRs in the absence of pre-formed seeds resulted in increased $A \beta-40$ fibrillation lag time and reduced fibril fluorescence intensity (Fig S8) which may be caused by depletion of $A \beta$ from solution via binding to Abs-GNRs. TEM was used to confirm that $A \beta$ fibrils formed in the presence or absence of seeds-Abs- 
GNRs show no morphological differences, with gold nanorods observed within fibrillar networks, suggesting incorporation of bound seeds during the fibrillation process (Fig 5, c and d).

a)

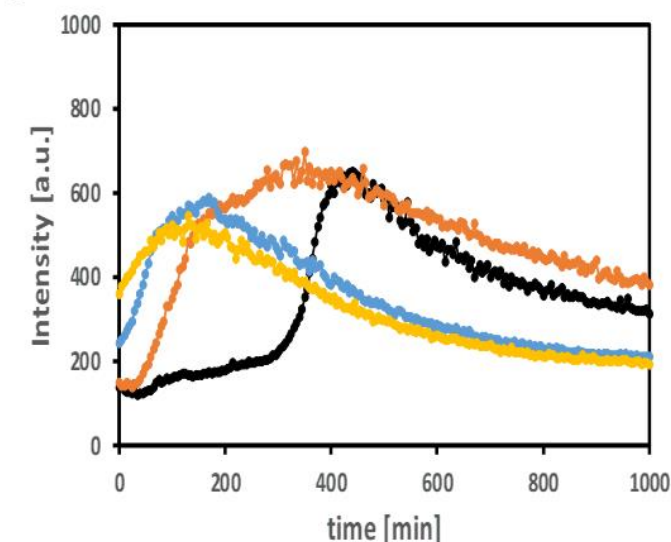

c)

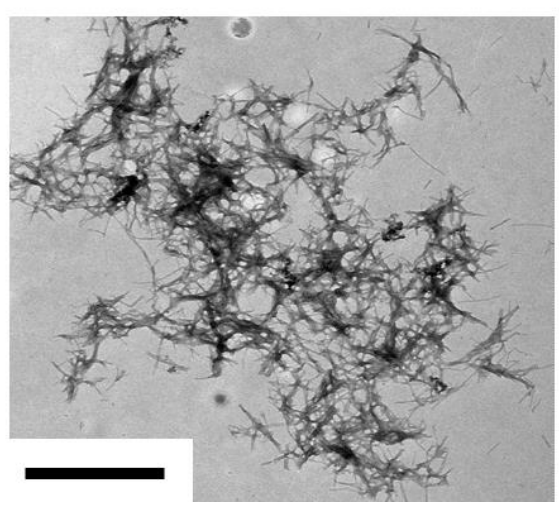

b)

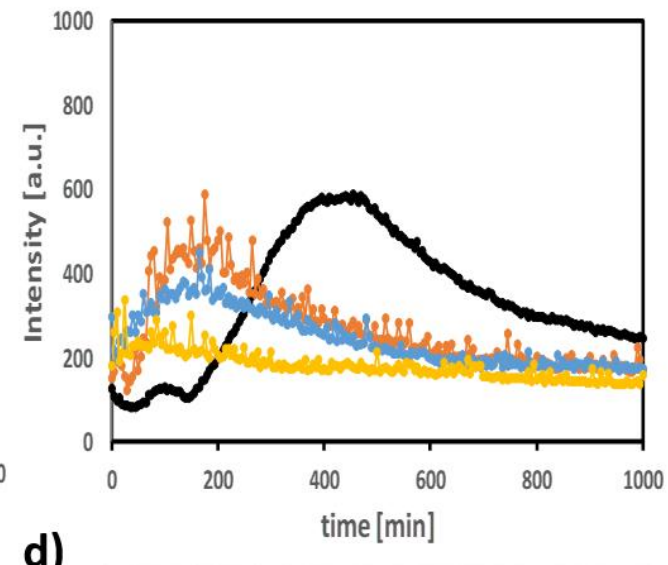

d)

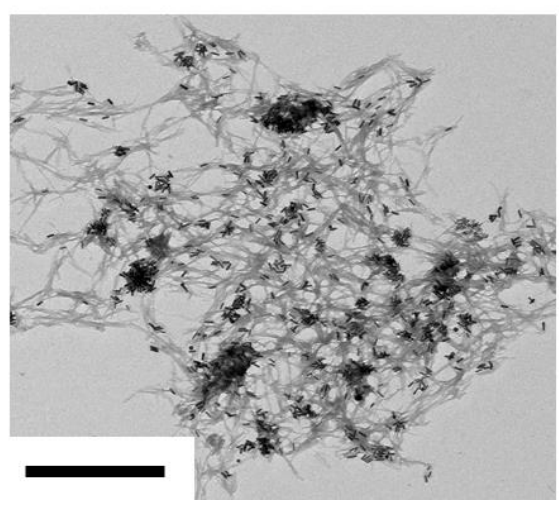

Fig 5. Seeds-Abs-GNRs complexes retain seeding ability and can be integrated into fibrillar networks. a) Aggregation kinetics assessed by ThT fluorescence of $10 \mu \mathrm{M}$ Aß40 in PBS (pH 7.4, $37^{\circ} \mathrm{C}$ ) in absence (black) or presence of seeds at varying concentrations; $0.1 \mu \mathrm{M}$ (orange), $0.5 \mu \mathrm{M}$ (light blue), and $1 \mu \mathrm{M}$ (yellow). b) ThT fluorescence of $10 \mu \mathrm{M}$ Aß40 incubated in absence (black) or presence of pre-formed seeds-Abs-GNRs formed from $0.4 \mathrm{nM}$ of Abs-GNRs with increasing concentrations of seeds as above $0.1 \mu \mathrm{M}$ (orange), $0.5 \mu \mathrm{M}$ (light blue), and $1 \mu \mathrm{M}$ (yellow). TEM images of $10 \mu \mathrm{M}$ Aß40 incubated in PBS, pH 7.4 for $10 \mathrm{~h}$ at $37^{\circ} \mathrm{C}$ in the presence of c) plain seeds and d) seeds-Abs-GNRs, confirming that seeds-Abs-GNR complexes are integrated within fibrillar networks. Scale bars correspond to $1 \mu \mathrm{m}$. 


\section{Optoacoustic imaging of seeds-Abs-GNR complexes}

MSOT data was collected using agar phantoms to test sensitivity and optical properties of seeds-AbsGNR complexes. A range of seeds-Abs-GNR complexes concentrations (5-500 pM) were imaged and recorded at wavelengths 680 to $950 \mathrm{~nm}$. As expected, the strength of the photoacoustic signal detected by MSOT correlates with the absorbance over this range of wavelengths (Fig 6a). This is associated with a gradual change in the MOST signal intensity at different wavelengths as shown in the single wavelength images (Fig 6b). The MSOT signal was found to be linearly dependent on concentration (Fig 6c). At $5 \mathrm{pM}$, the lowest tested concentration, the unmixed MSOT signal is still detectable separately from the background noise of the agar phantom (Fig 6d) which is encouraging for future applications. Previous studies injected A $\beta$ seeds at concentrations of $10-20 \mathrm{ng} / \mu 1 .[10]$ We have made our $\mathrm{A} \beta$-Abs-GNR complexes consistent with this concentration of $\sim 2 \mu \mathrm{M} A \beta$ and $500 \mathrm{pM}$ gold nanorods. MSOT data suggests that even with dilution of seeds upon injection that may occur sufficient signal would remain to enable tracking of seeds in vivo. Estimating precisely the in vivo limit of detection is a highly complex issue because sensitivity is affected by tissue depth, the absorption profiles of various organs, attenuation by tissues, as well as the number of wavelengths selected for acquisition [40, 41]. Further calibration work in vivo will be required to precisely establish the amount of AbsGNRs that can be tracked. 
a)

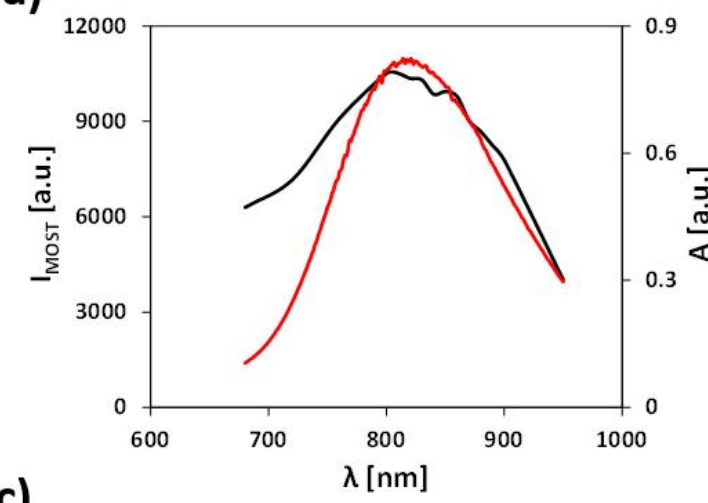

c)

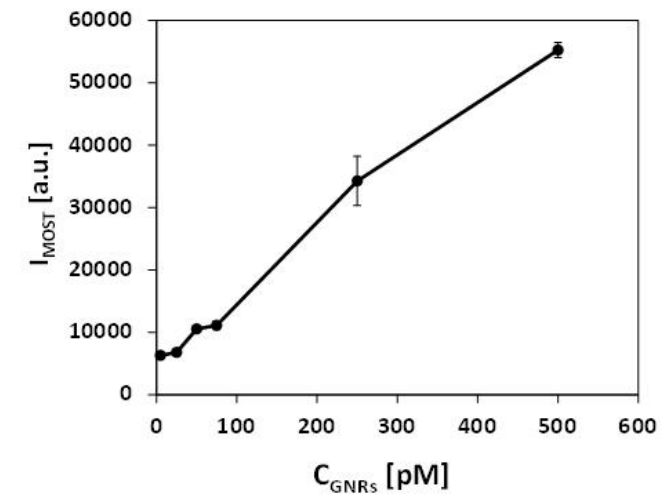

b)

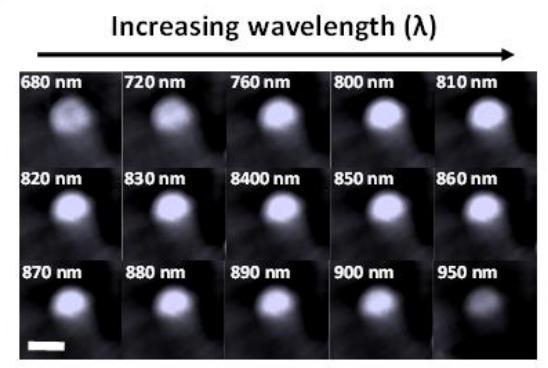

d)

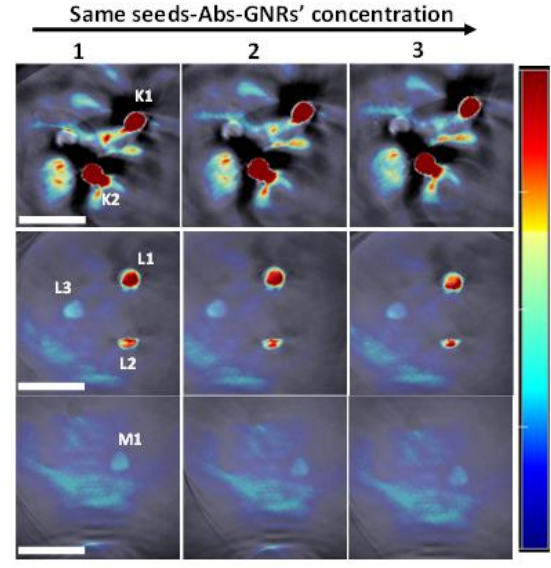

Fig 6. Phantom MSOT experiments. a) Comparison of MSOT intensity signals (black) and UV spectrum (red) of A $\beta$-seeds-GNRs agar phantom. b) Corresponding single wavelength MSOT images $(680-950 \mathrm{~nm})$. Scale bar is $3 \mathrm{~mm}$ for all images. c) Average MSOT signal intensities collected from 3 different positions for increasing concentrations of seeds-Abs-GNRs (5-500 pM). d) Corresponding multispectral unmixed MSOT images. Concentration of seeds-Abs-GNRs; Top-500 pM (K1), 250 pM (K2), Middle-75 pM (L1), 50 pM (L2), 25 pM (L3), Bottom-5 pM (M1). Images were reconstructed from raw signal data captured with the MSOT system at 3 different positions $(1,2 \& 3)$ with a logarithmic colour bar. Scale bars are $10 \mathrm{~mm}$. Colour scale range is 1.2 $\times 10^{3}$ to $1.2 \times 10^{4}$ MSOT au (same scale is used in all MSOT images).

\section{Conclusions}

In this work we have exploited the selectivity of antibodies conjugated to gold nanorods to bind to preformed $A \beta$ seeds to design an optoacoustic imaging tool for monitoring the propagation of $A \beta$ seeds in vivo. The resulting probes have been characterised to be stable, non-toxic and biocompatible while 
retaining their ability to seed fibril formation comparable with that observed by seeds alone. Preliminary MSOT data demonstrate that the optical signature of gold nanorods was preserved in the complexes and that signal could be detected at concentrations as low as $5 \mathrm{pM}$. These complexes provide a suitable optical probe to monitor the propagation of $\mathrm{A} \beta$-seeds by MSOT in an in vivo model to contribute to a better understanding of the role of $\mathrm{A} \beta$ seeds in Alzheimer's disease progression.

\section{Acknowledgements}

We thank BioLegend for their support with providing antibodies for this project and Alzheimer's Research UK for pilot project funding (ARUK-PPG2017B-019).

\section{References}

1. Braak H, Braak E. Neuropathological stageing of Alzheimer-related changes. Acta Neuropathol. 1991;82(4):239-59.

2. Westermark GT, Westermark P. Prion-like aggregates: infectious agents in human disease. Trends Mol Med. 2010;16(11):501-7.

3. Cohen M, Appleby B, Safar JG. Distinct prion-like strains of amyloid beta implicated in phenotypic diversity of Alzheimer's disease. Prion. 2016;10(1):9-17.

4. Jucker M, Walker LC. Pathogenic Protein Seeding in Alzheimer Disease and Other Neurodegenerative Disorders. Ann Neurol. 2011;70(4):532-40.

5. Luk KC, Kehm V, Carroll J, Zhang B, O'Brien P, Trojanowski JQ, et al. Pathological $\alpha-$ Synuclein Transmission Initiates Parkinson-like Neurodegeneration in Nontransgenic Mice. Science. 2012;338(6109):949-53

6. Pecho-Vrieseling E, Rieker C, Fuchs S, Bleckmann D, Esposito MS, Botta P, et al. Transneuronal propagation of mutant huntingtin contributes to non-cell autonomous pathology in neurons. Nat Neurosci. 2014;17(8):1064-72.

7. Kisilevsky R. Preparation and Propagation of Amyloid-Enhancing Factor. In: Sigurdsson EM, editor. Amyloid Proteins: Methods and Protocols. Totowa, NJ: Humana Press; 2005. p. 237-41. 
8. Stangou AJ, Hawkins PN, Heaton ND, Rela M, Monaghan M, Nihoyannopoulos P, et al. Progressive cardiac amyloidosis following liver transplantation for familial amyloid polyneuropathy: implications for amyloid fibrillogenesis. Transplantation. 1998;66(2):229-33.

9. Meyer-Luehmann M, Coomaraswamy J, Bolmont T, Kaeser S, Schaefer C, Kilger E, et al. Exogenous Induction of Cerebral ß-Amyloidogenesis Is Governed by Agent and Host. Science. 2006;313(5794):1781-4.

10. Eisele YS, Obermüller U, Heilbronner G, Baumann F, Kaeser SA, Wolburg H, et al. Peripherally Applied A $\beta$-Containing Inoculates Induce Cerebral $\beta$-Amyloidosis. Science. 2010;330(6006):980-2.

11. Jaunmuktane Z, Mead S, Ellis M, Wadsworth JDF, Nicoll AJ, Kenny J, et al. Evidence for human transmission of amyloid-[bgr] pathology and cerebral amyloid angiopathy. Nature. 2015;525(7568):247-50

12. Feeney C, Scott GP, Cole JH, Sastre M, Goldstone AP, Leech R. Seeds of neuroendocrine doubt. Nature. 2016;535(7611):E1-E2.

13. Collinge J, Jaunmuktane Z, Mead S, Rudge P, Brandner S. Collinge et al. reply. Nature. 2016;535(7611):E2-E3.

14. $\quad$ https://pubpeer.com/publications/3DFF9716AA8B5D4167FDDFE48C6294.

15. Sponarova J, Nyström SN, Westermark GT. AA-amyloidosis can be transferred by peripheral blood monocytes. PloS one. 2008;3(10):e3308-e.

16. Cui D, Kawano H, Hoshii Y, Liu Y, Ishihara T. Acceleration of murine AA amyloid deposition by bovine amyloid fibrils and tissue homogenates. Amyloid. 2008;15(2):77-83.

17. Zhang B, Une Y, Fu X, Yan J, Ge F, Yao J, et al. Fecal transmission of AA amyloidosis in the cheetah contributes to high incidence of disease. Proc Natl Acad Sci U S A. 2008;105(20):7263-8.

18. Bell AG. The production of sound by radiant energy. Science. 1881;os-2(49):242-53.

19. Stoffels I, Morscher S, Helfrich I, Hillen U, Leyh J, Burton NC, et al. Metastatic status of sentinel lymph nodes in melanoma determined noninvasively with multispectral optoacoustic imaging. Science Translational Medicine. 2015;7(317):317ra199-317ra199. 
20. Comenge J, Sharkey J, Fragueiro O, Wilm B, Brust M, Murray P, et al. Multimodal cell tracking from systemic administration to tumour growth by combining gold nanorods and reporter genes. eLife. 2018;7:e33140.

21. Comenge J, Fragueiro O, Sharkey J, Taylor A, Held M, Burton NC, et al. Preventing Plasmon Coupling between Gold Nanorods Improves the Sensitivity of Photoacoustic Detection of Labeled Stem Cells in Vivo. ACS Nano. 2016;10(7):7106-16.

22. Ntziachristos V, Razansky D. Molecular Imaging by Means of Multispectral Optoacoustic Tomography (MSOT). Chemical Reviews. 2010;110(5):2783-94.

23. Wang LV. Multiscale photoacoustic microscopy and computed tomography. Nat Photonics. 2009;3(9):503-9.

24. Huang X, Neretina S, El-Sayed MA. Gold Nanorods: From Synthesis and Properties to Biological and Biomedical Applications. Advanced Materials. 2009;21(48):4880-910.

25. Taruttis A, Herzog E, Razansky D, Ntziachristos V. Real-time imaging of cardiovascular dynamics and circulating gold nanorods with multispectral optoacoustic tomography. Opt Express. 2010;18(19):19592-602.

26. Taruttis A, Lozano N, Nunes A, Jasim DA, Beziere N, Herzog E, et al. siRNA liposome-gold nanorod vectors for multispectral optoacoustic tomography theranostics. Nanoscale. 2014;6(22):134516.

27. Ye X, Jin L, Caglayan H, Chen J, Xing G, Zheng C, et al. Improved Size-Tunable Synthesis of Monodisperse Gold Nanorods through the Use of Aromatic Additives. ACS Nano. 2012;6(3):2804-17. 28. Soliman MG, Pelaz B, Parak WJ, del Pino P. Phase Transfer and Polymer Coating Methods toward Improving the Stability of Metallic Nanoparticles for Biological Applications. Chemistry of Materials. 2015;27(3):990-7.

29. Xu M, Soliman MG, Sun X, Pelaz B, Feliu N, Parak WJ, et al. How Entanglement of Different Physicochemical Properties Complicates the Prediction of in Vitro and in Vivo Interactions of Gold Nanoparticles. ACS Nano. 2018;12(10):10104-13. 
30. Lin C-AJ, Sperling RA, Li JK, Yang T-Y, Li P-Y, Zanella M, et al. Design of an Amphiphilic Polymer for Nanoparticle Coating and Functionalization. Small (Weinheim an der Bergstrasse, Germany). 2008;4(3):334-41.

31. Bartczak D, Kanaras AG. Preparation of Peptide-Functionalized Gold Nanoparticles Using One Pot EDC/Sulfo-NHS Coupling. Langmuir : the ACS journal of surfaces and colloids. 2011;27(16):10119-23.

32. Mirsadeghi S, Dinarvand R, Ghahremani MH, Hormozi-Nezhad MR, Mahmoudi Z, Hajipour MJ, et al. Protein corona composition of gold nanoparticles/nanorods affects amyloid beta fibrillation process. Nanoscale. 2015;7(11):5004-13.

33. O'Brien J, Wilson I, Orton T, Pognan F. Investigation of the Alamar Blue (resazurin) fluorescent dye for the assessment of mammalian cell cytotoxicity. European journal of biochemistry / FEBS. 2000;267(17):5421-6.

34. Tripathi K, Driskell JD. Quantifying Bound and Active Antibodies Conjugated to Gold Nanoparticles: A Comprehensive and Robust Approach To Evaluate Immobilization Chemistry. ACS Omega. 2018;3(7):8253-9.

35. Krpetic Z, Davidson AM, Volk M, Levy R, Brust M, Cooper DL. High-resolution sizing of monolayer-protected gold clusters by differential centrifugal sedimentation. ACS Nano. 2013;7(10):8881-90.

36. Davidson AM, Brust M, Cooper DL, Volk M. Sensitive Analysis of Protein Adsorption to Colloidal Gold by Differential Centrifugal Sedimentation. Anal Chem. 2017;89(12):6807-14.

37. Taheri RA, Akhtari Y, Tohidi Moghadam T, Ranjbar B. Assembly of Gold Nanorods on HSA Amyloid Fibrils to Develop a Conductive Nanoscaffold for Potential Biomedical and Biosensing Applications. Scientific reports. 2018;8(1):9333.

38. Sun X, Gamal M, Nold P, Said A, Chakraborty I, Pelaz B, et al. Tracking stem cells and macrophages with gold and iron oxide nanoparticles - The choice of the best suited particles. Applied Materials Today. 2019;15:267-79. 
39. Phelan MM, Caamaño-Gutiérrez E, Gant MS, Grosman RX, Madine J. Using an NMR metabolomics approach to investigate the pathogenicity of amyloid-beta and alpha-synuclein. Metabolomics. 2017;13(12):151.

40. Razansky D, Baeten J, Ntziachristos V. Sensitivity of molecular target detection by multispectral optoacoustic tomography (MSOT). Medical Physics. 2009;36(3):939-45.

41. Tzoumas S, Nunes A, Deliolanis NC, Ntziachristos V. Effects of multispectral excitation on the sensitivity of molecular optoacoustic imaging. Journal of Biophotonics. 2015;8(8):629-37. 
bioRxiv preprint doi: https://doi.org/10.1101/2021 10.25.465704 - this version posted October 25, 2021. The copyright holder for this preprint (which was not certified by peer review) is the author/funder, who has granted bioRxiv a license to display the preprint in perpetuity. It is made available under aCC-BY 4.0 International license.

\section{Supporting Information}

Table S1. Experimental conditions used for the phase transfer, polymer coating and anti-AB anybody conjugation. $\mathrm{c}_{\mathrm{NP}}, \mathrm{c}_{\mathrm{DDA}}$ and $\mathrm{c}_{\mathrm{PEG}}$ refers to the concentration of gold nanorods, dodecylamine and PEG, respectively. $\mathrm{R}_{\mathrm{p} / \mathrm{Area}}$ refers to the number of PMA monomer added per $\mathrm{nm}^{2}$ of effective NP surface. a refers to the centrifugation acceleration $\left(g=9.81 \mathrm{~m} / \mathrm{s}^{2}\right)$ and $\mathrm{t}$ refers to the centrifugation time.

\begin{tabular}{|c|c|c|c|c|c|}
\hline \multirow{3}{*}{ Sample } & \multicolumn{2}{|c|}{ Phase transfer } & \multicolumn{3}{|c|}{ Polymer coating } \\
\hline & \multirow[b]{2}{*}{$\mathbf{c}_{\mathrm{PEG}} / \mathbf{c}_{\mathrm{NP}}$} & \multirow[b]{2}{*}{$\mathbf{c}_{\mathrm{DDA}}[\mathbf{M}]$} & \multirow{2}{*}{$\begin{array}{l}\mathbf{R}_{\mathbf{P}} / \text { Area } \\
{\left[\mathbf{n m}^{-2}\right]}\end{array}$} & \multicolumn{2}{|c|}{ Centrifugation } \\
\hline & & & & $\mathbf{a}[\mathrm{g}]$ & $\begin{array}{c}\mathbf{t} \\
{[\mathrm{min}]}\end{array}$ \\
\hline GNRs & $3 \cdot 10^{4}$ & 75 & 3000 & 8960 & 30 \\
\hline
\end{tabular}


Table S2. EDC/sulfo-NHS coupling reaction of Abs-A $\beta$ to PMA-GNRs under different concentrations of EDC/sulfo-NHS at a fixed concentration of Abs-A $\beta$ (sampled coded "a") or different concentrations of $\mathrm{Abs}-\mathrm{A} \beta$ at a fixed concentration of coupling reagents (samples coded "b"). The ratio between EDC and sulfo-NHS was always kept constant at 1:2, respectively.

\begin{tabular}{|c|c|c|c|c|}
\hline Condition & $\begin{array}{r}\text { Abs-A } \beta \\
{[\mu \mathrm{g} / \mathrm{mL}]}\end{array}$ & $\begin{array}{c}\text { EDC } \\
\text { [mmoles }]\end{array}$ & $\begin{array}{r}\text { sulfo-NHS } \\
\text { [mmoles] }\end{array}$ & $\begin{array}{c}\text { LSPR shifting } \\
\text { [nm] }\end{array}$ \\
\hline $1 \mathrm{a}$ & 0 & 0 & 0 & Control \\
\hline $2 a$ & \multirow{5}{*}{50} & 0 & 0 & 0 \\
\hline $3 a$ & & 0.5 & 1 & $\sim 2$ \\
\hline $4 a$ & & 1 & 2 & $\sim 3$ \\
\hline $5 a$ & & 2 & 4 & $\sim 5$ \\
\hline $6 a$ & & 4 & 8 & $\sim 5$ \\
\hline $1 \mathrm{~b}$ & 0 & 0 & 0 & Control \\
\hline $2 b$ & 5 & \multirow{4}{*}{2} & \multirow{4}{*}{4} & 0 \\
\hline $3 b$ & 20 & & & $\sim 2$ \\
\hline $4 b$ & 50 & & & $\sim 5$ \\
\hline $5 b$ & 75 & & & $\sim 5$ \\
\hline
\end{tabular}


bioRxiv preprint doi: https://doi.org/10.1101/2021.10.25.465704; this version posted October 25,2021 . The copyright holder for this preprint (which was not certified by peer review) is the author/funder, who has granted bioRxiv a license to display the preprint in perpetuity. It is made available under aCC-BY 4.0 International license.

Table S3. Hydrodynamic diameter $d_{h}[n m]$ in number $\left(d_{h(N)}\right)$ and intensity $\left(d_{h(I)}\right)$, Z-average $\left(d_{h(Z)}\right)$, polydispersity index (PDI) and $\zeta$-potential values $(\zeta)$ for gold nanorods along their surface modification and upon conjugation with $\mathbf{A} \boldsymbol{\beta}$ seeds. Size values for gold nanorods, although without any physical meaning because they are not spherical NPs, are included to show that the colloidal stability was not compromised in the different steps of the polymer coating.

\begin{tabular}{|c|c|c|c|c|c|c|c|}
\hline Sample & Coating & $d_{h, N}[n m]$ & $d_{h, Z}[\mathrm{~nm}]$ & PDI & $\mathbf{d}_{\mathrm{h}, \mathbf{I 1}}[\mathrm{nm}]$ & $d_{\mathrm{h}, \mathrm{I} 2}[\mathrm{~nm}]$ & $\zeta[\mathrm{mV}]$ \\
\hline \multirow{4}{*}{ GNRs } & CTAB & $3.65 \pm 0.05$ & $7.87 \pm 0.25$ & $0.3 \pm 0.01$ & $6.62 \pm 0.01$ & $99.49 \pm 1.65$ & $\begin{array}{c}+34.1 \pm \\
1.15\end{array}$ \\
\hline & DDA & $2.75 \pm 0.03$ & $8.0 \pm 0.19$ & $0.3 \pm 0.01$ & $4.77 \pm 0.02$ & $79.82 \pm 1.06$ & - \\
\hline & PMA & $3.90 \pm 0.1$ & $10.38 \pm 0.1$ & $0.4 \pm 0.008$ & $7.69 \pm 0.16$ & $89.54 \pm 1.87$ & $\begin{array}{c}-28.8 \pm \\
0.26\end{array}$ \\
\hline & Abs & $4.5 \pm 0.3$ & $12.29 \pm 0.09$ & $0.4 \pm 0.006$ & $8.25 \pm 0.2$ & $97.54 \pm 1.2$ & $\begin{array}{c}-17.7 \pm \\
1.75\end{array}$ \\
\hline Plain A $\beta$ Seeds & - & - & - & - & - & - & $\begin{array}{c}-44.2 \pm \\
1.10\end{array}$ \\
\hline $\begin{array}{c}\text { A } \beta \text { Seeds- } \\
\text { GNRs }\end{array}$ & - & - & - & - & - & - & $\begin{array}{c}-43.7 \pm \\
0.30\end{array}$ \\
\hline
\end{tabular}



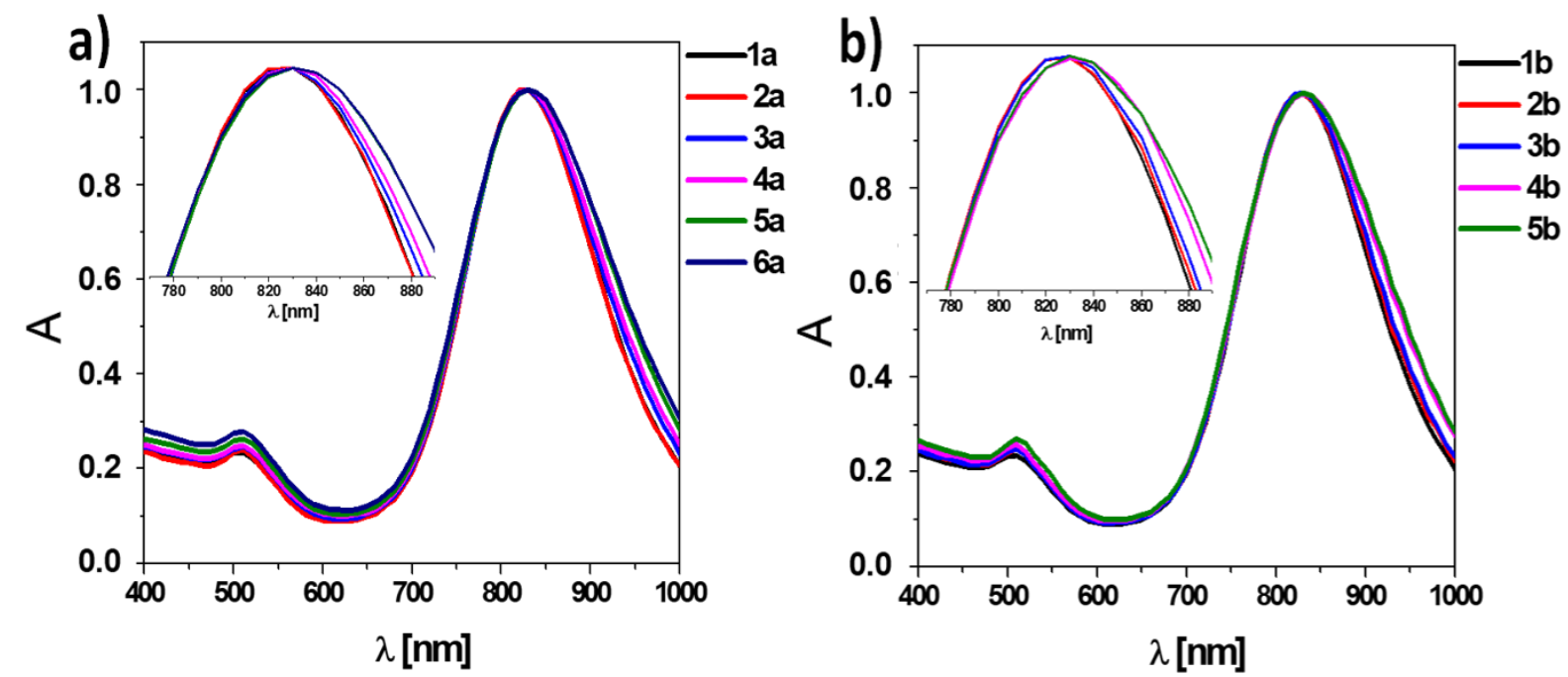

Figure S1. Normalized absorption spectra for PMA-GNRs before and after conjugation with AbsA $\beta$ under different experimental conditions using EDC/sulfo-NHS. a) The concentration of EDC/sulfo- NHS was varied while the concentration of Abs-A $\beta$ was fixed. $b$ ) The concentration of Abs$\mathrm{A} \beta$ was varied while the concentration of EDC/sulfo-NHS was kept constant. The experimental conditions are listed in Table S2. 

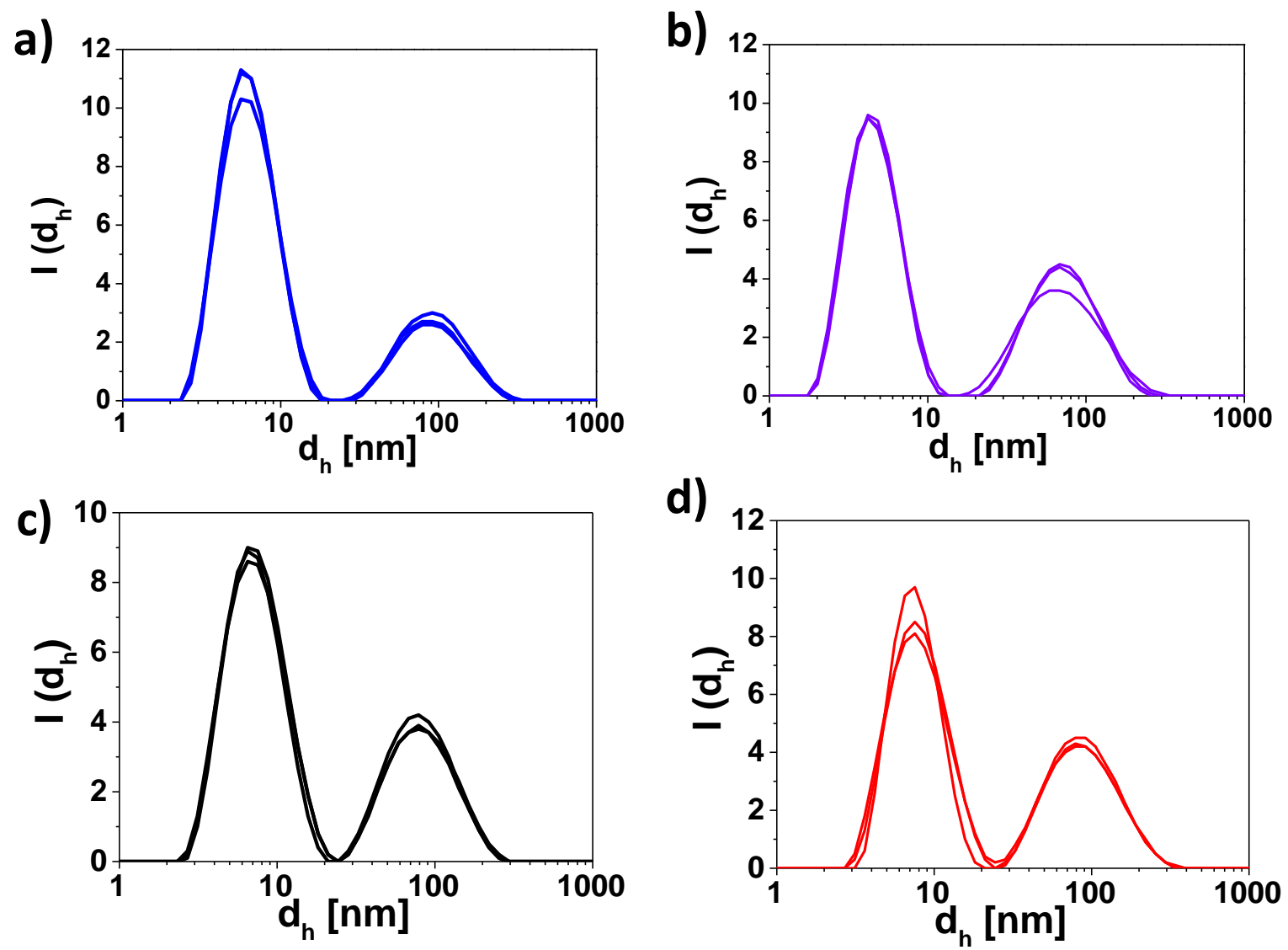

Figure S2. Intensity distribution of hydrodynamic diameters $\left(I\left(d_{h}\right)\right)$ for gold nanorods along their surface modification. a) CTAB-capped; b) DDA-capped; c) PMA-coated and d) after conjugation with anti-A $\beta$ antibody. 

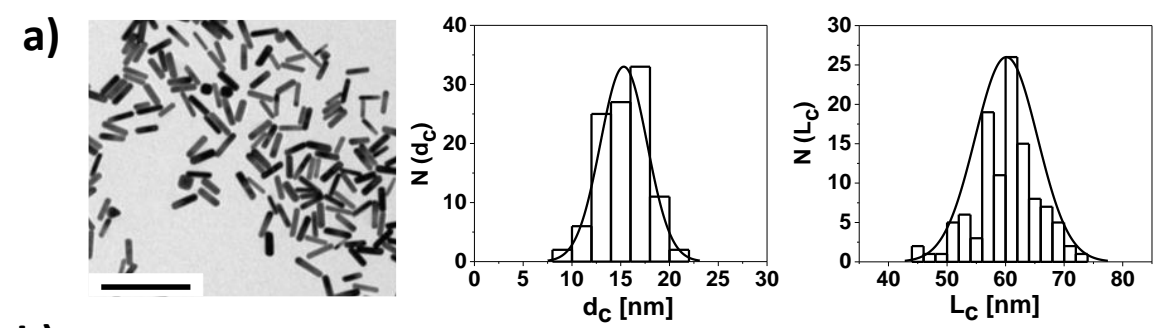

b)
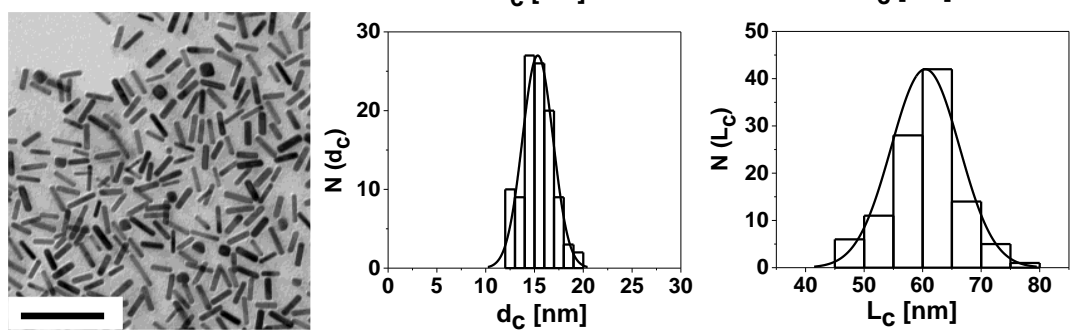

c)
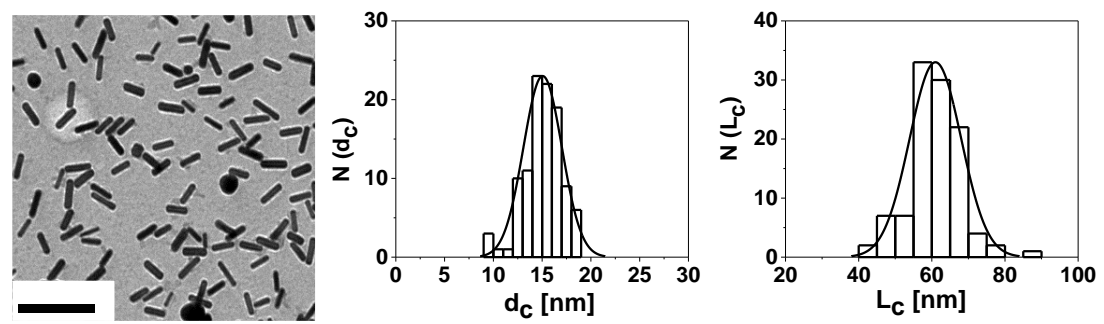

Figure S3. TEM images of gold nanorods and their corresponding size distribution histograms after different steps of surface modifications, plotted as number of NPs. $N\left(d_{c}\right)$ that have a core diameter of $d_{c}$ (histograms to the left) and as number of NPs $N\left(L_{c}\right)$ that have a core length of $L_{c}$ (histograms to the right). A) CTAB coated gold nanorods with $\mathrm{d}_{\mathrm{c}}=15.31 \pm 2.39 \mathrm{~nm}$, and $\mathrm{L}_{\mathrm{c}}=60.13 \pm$ $5.33 \mathrm{~nm}$. B) PMA coated gold nanorods with $\mathrm{d}_{\mathrm{c}}=15.25 \pm 1.68 \mathrm{~nm}$, and $\mathrm{L}_{\mathrm{c}}=59.90 \pm 5.85 \mathrm{~nm}$. C) Ab conjugated gold nanorods with $\mathrm{d}_{\mathrm{c}}=14.91 \pm 1.97 \mathrm{~nm}$, and $\mathrm{L}_{\mathrm{c}}=60.987 .06 \mathrm{~nm}$. The scale bars correspond to $200 \mathrm{~nm}$. 


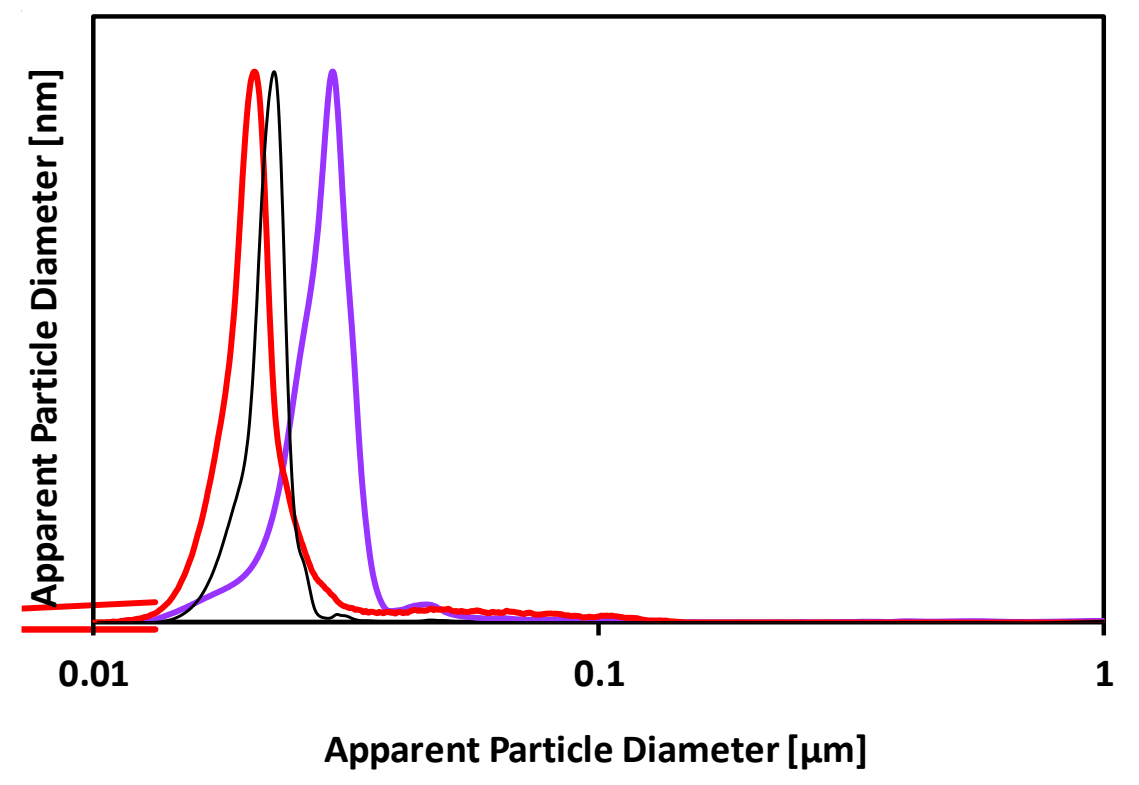

Figure S4. Apparent size distributions measured by analytical disc centrifugation (CPS). CTAB-capped gold nanorods (purple), PMA-coated GNRs (black) and $A \beta$ antibodies conjugated PMA-GNRs (red). The average values are $29.8 \pm 0.2 \mathrm{~nm}, 22.79 \pm 0.12 \mathrm{~nm}$ and $20.81 \pm 0.18 \mathrm{~nm}$ respectively. 
a)
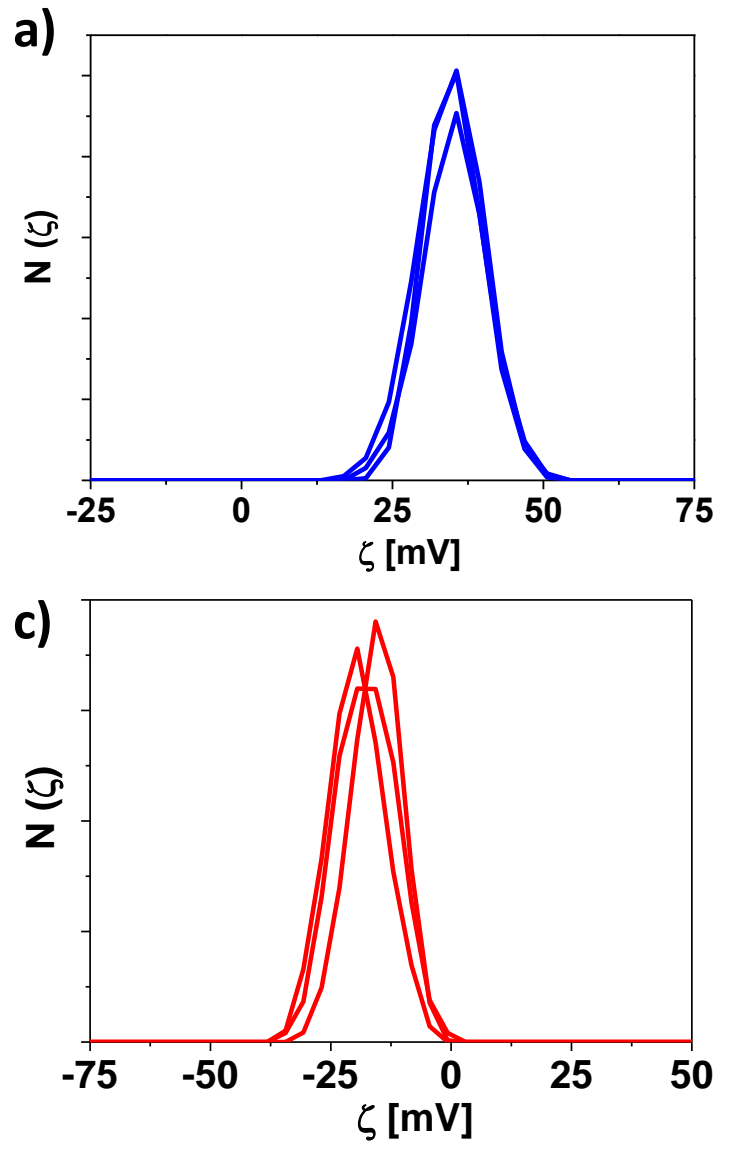

b)
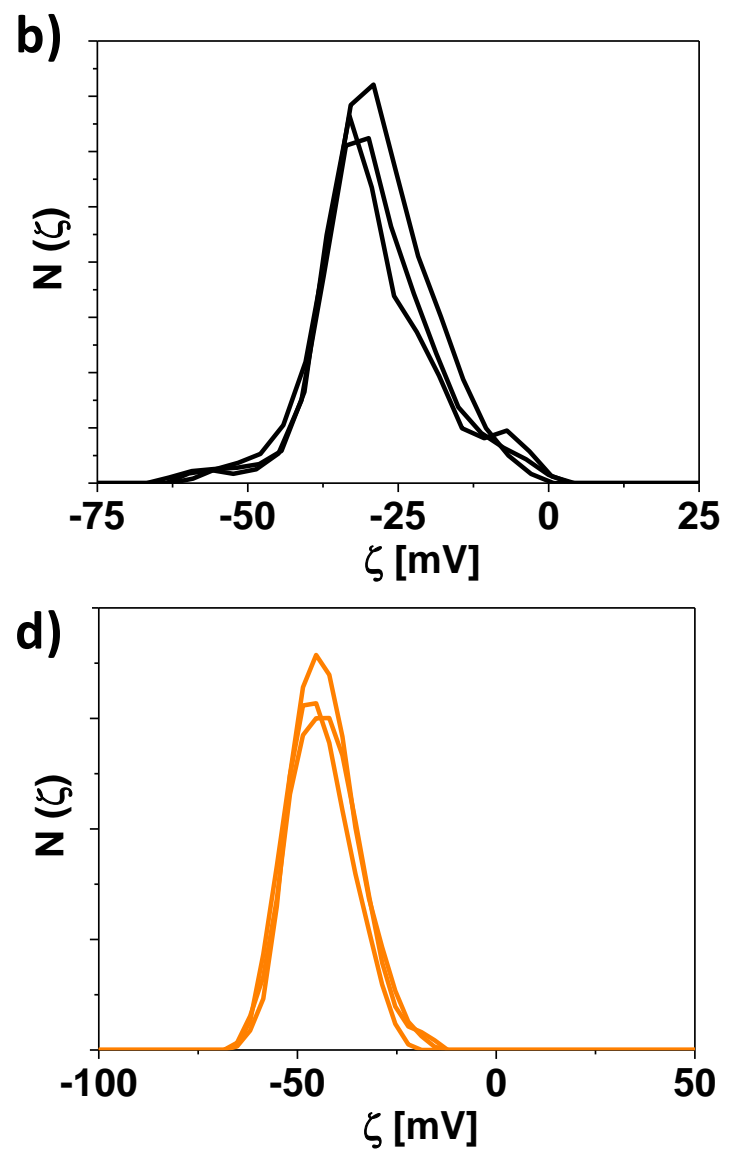

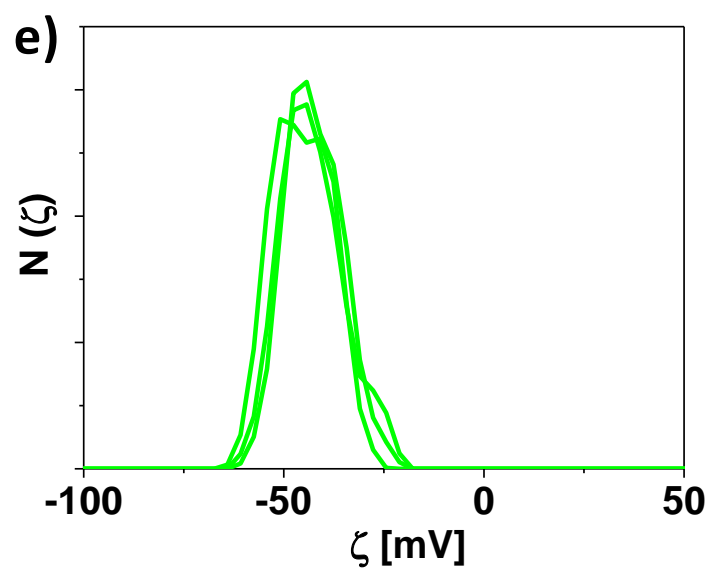

Figure S5. $\zeta$-potential distribution $(\mathrm{N}(\zeta))$ results during gold nanorods surface modification process. a) CTAB-capped; b) PMA-coated; c) after conjugation with anti-A $\beta$ antibodies and d) after complex formation of Abs-GNRs attached to $A \beta$ seeds, e) $A \beta$ seeds alone. 
a
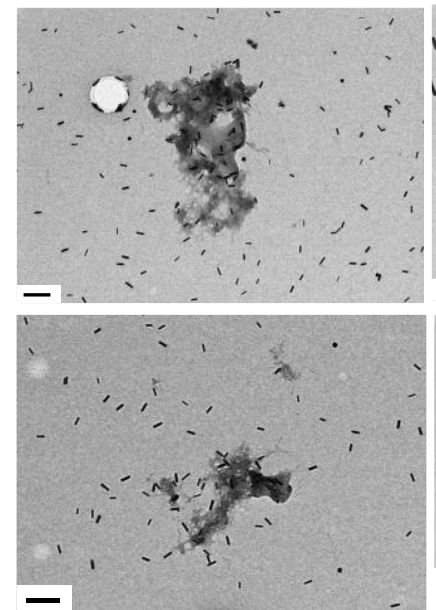
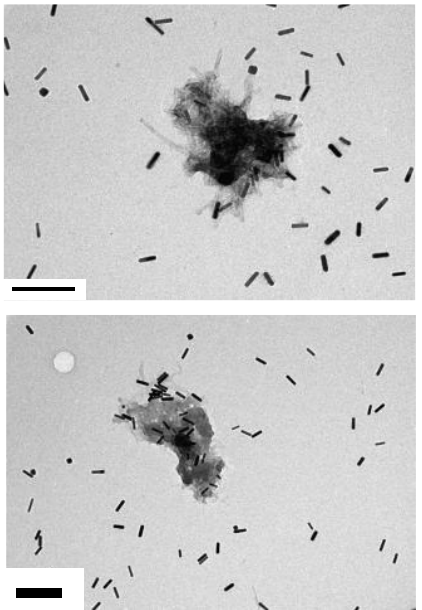

b

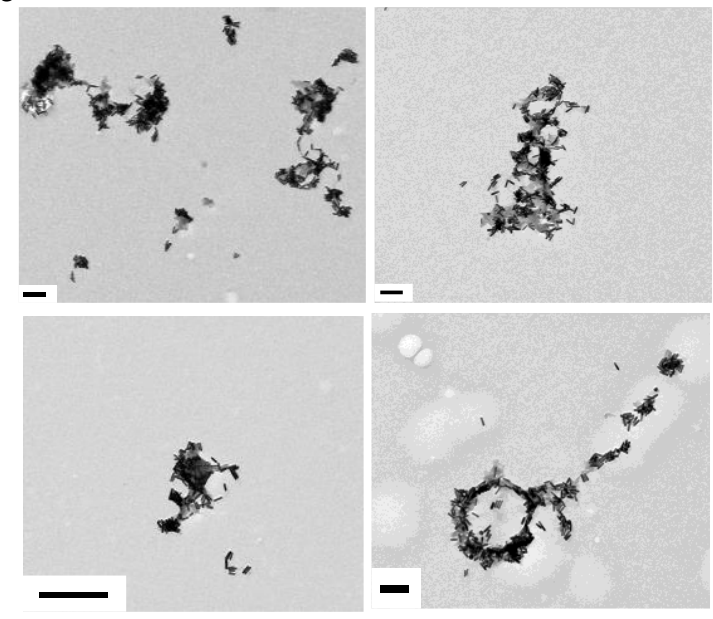

Figure S6. Additional TEM images. a) PMA-GNRs and b) Abs-GNRs after incubation with A $\beta$ seeds overnight. The scale bars correspond to $200 \mathrm{~nm}$. 

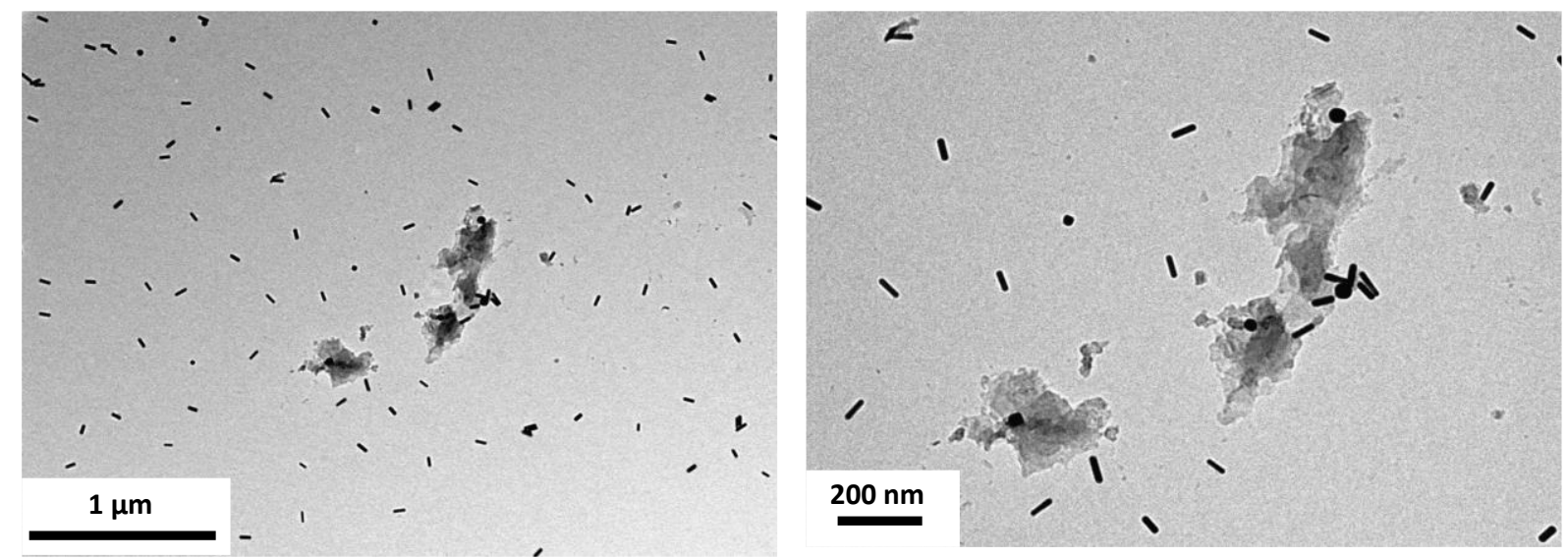

Figure S7. TEM images of Abs-GNRS incubated overnight with seeds formed from a control amyloidogenic protein medin. Scale bars are as shown. 
a)

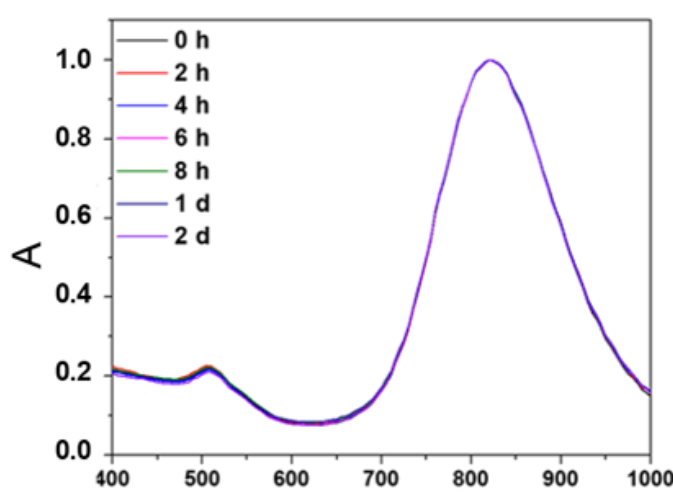

b)

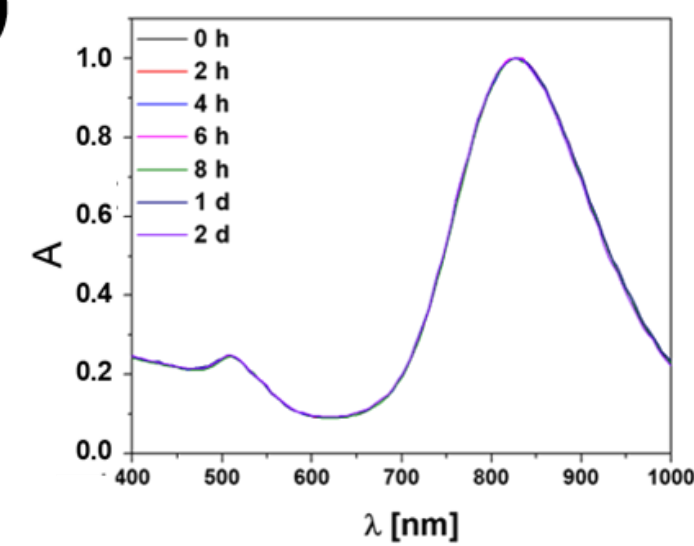

c)

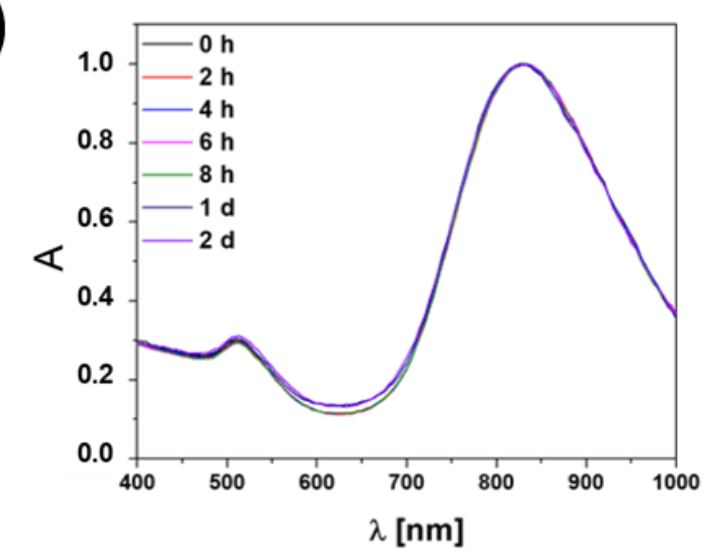

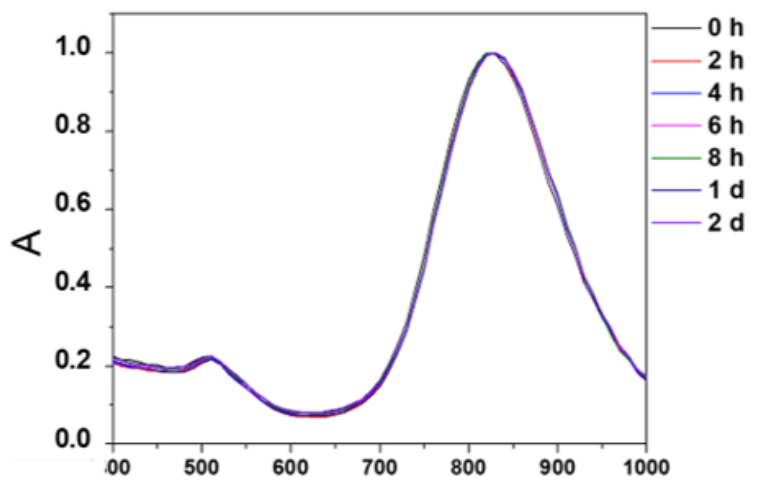

$\lambda[\mathrm{nm}]$
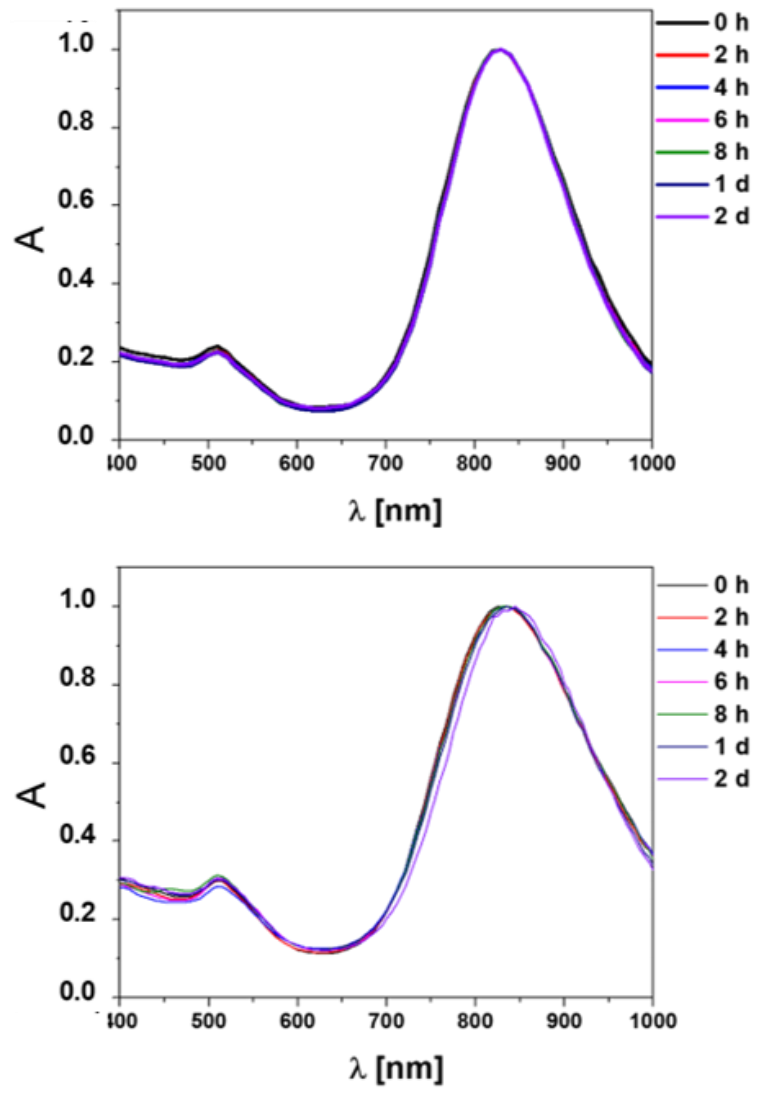

Figure S8. Normalized absorption spectra. a) PMA- GNRs, b) Abs- GNRs, and c) seeds-Abs-GNRs in water (left) and cell media (right) at different point of times (up to 2 days). 


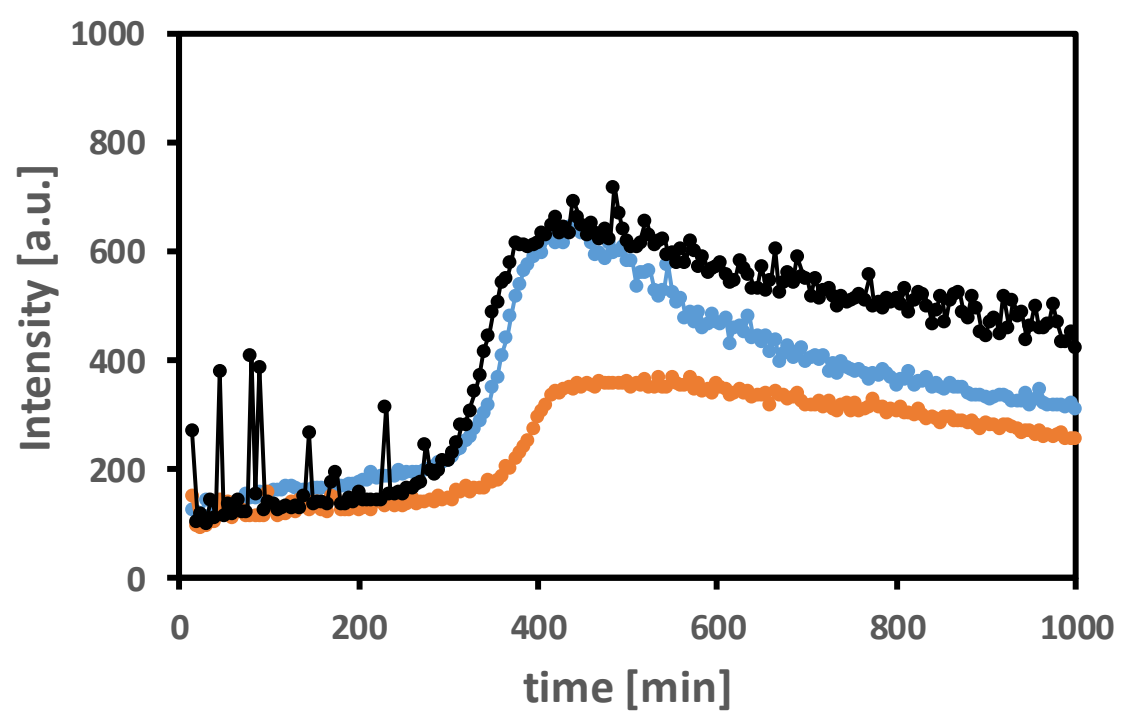

Figure S9. PMA-GNRs do not bind to or alter A $\beta 40$ fibrillation. ThT fluorescence of $10 \mu \mathrm{M} A \beta 40$ in PBS (pH 7.4, $37^{\circ} \mathrm{C}$ ) alone (black), and in the presence of PMA-GNRs (light blue) or Abs-GNRs (orange). 


\section{Appendix}

\section{Calculating the amount of PMA needed for phase transfer of NPs from organic solvent to aqueous medium}

To determine the amount of polymer which is needed for the coating of the NPs, a calculation based on the total NP surface to be coated was done following the calculations previously reported by Pellegrino et al., in which the total effective surface area of one nanoparticle $\left(\mathrm{A}_{\text {eff }}\right)$ is calculated in agreement with its shape. Nanorodswere considered as cylinders to simplify the calculations. In this case, the effective diameter $\left(\mathrm{d}_{\mathrm{eff}}\right)$ value included the diameter of the Au core as determined by transmission electron micoscopy (TEM) $\left(\mathrm{d}_{\mathrm{c}}\right.$, cf. section 3$)$ plus two times the assumed thickness of the surfactant shell $\left(\mathrm{L}_{\mathrm{s}}=\right.$ $1 \mathrm{~nm})$. Once the surface of one NP is determined then, knowing the NPs concentration $\left(\mathrm{c}_{\mathrm{NP}}\right)$ and the volume of the NP solution to be coated $\left(\mathrm{V}_{\mathrm{NP}, \mathrm{sol}}\right)$, the total area $\left(\mathrm{A}_{\mathrm{tot}}\right)$ of the NPs in the solution can be determined by the formula (S1):

$$
A_{\text {eff }}=2 \pi \cdot\left(\frac{\left(d_{c}+2 L_{s}\right)}{2}\right) \cdot\left(L_{c}+2 L_{s}\right)
$$

$A_{\text {eff }}$ is the effective surface area of one NP including the organic surfactant layer, $d_{c}$ is the diameter of the $\mathrm{Au}$ core and $\mathrm{L}_{\mathrm{c}}$ is the length of Au core of the gold nanorodsas determined by TEM. $\mathrm{L}_{\mathrm{s}}$ corresponds to the thickness of the surfactant layer and $\mathrm{d}_{\mathrm{eff}}$ is the effective diameter, equal to the NP core diameter determined by TEM $\left(d_{c}\right)$ plus two times the assumed thickness of the surfactant shell $\left(L_{s}=1 \mathrm{~nm}\right)$. The total effective surface area $\left(\mathrm{A}_{\mathrm{tot}}\right)$ of NPs thus is:

$$
A_{\text {tot }}=\mathrm{c}_{\mathrm{NP}} \cdot \mathrm{V}_{\mathrm{NP}, \mathrm{sol}} \cdot \mathrm{N}_{\mathrm{A}} \cdot \mathrm{A}_{\mathrm{eff}}
$$

$\mathrm{c}_{\mathrm{NP}}$ is the NP [M] concentration of the NP solution used of the coating. $\mathrm{V}_{\mathrm{NP}, \text { sol }}[\mathrm{L}]$ refers to the volume of the NP solution, and $\mathrm{N}_{\mathrm{A}}$ is the Avogadro constant. Then, the amount of polymer needed to be added to the NP solution can be determined by formula $\mathrm{S} 3$.

$$
\mathrm{V}_{\mathrm{P}}=\frac{\mathrm{N}_{\mathrm{P}}}{\mathrm{c}_{\mathrm{P}}}=\frac{\mathrm{A}_{\text {tot }} \cdot \mathrm{R}_{\mathrm{P} / \text { Area }}}{\mathrm{N}_{\mathrm{A}} \cdot \mathrm{c}_{\mathrm{P}}}
$$

$\mathrm{N}_{\mathrm{P}}$ [mol] is the amount of polymer molecules (given in terms of polymer monomers) needed to coat all the NPs in solution. $\mathrm{c}_{\mathrm{P}}[\mathrm{M}]$ is the concentration of the polymer stock solution. $\mathrm{V}_{\mathrm{P}}[\mathrm{L}]$ is the volume of polymer stock solution which needs to be added to the NP solution. $A_{\text {tot }}\left[\mathrm{nm}^{2}\right]$ is the total surface area of all the colloidal NPs in the solution and $\mathrm{R}_{\mathrm{P} / \mathrm{Area}}$ is the number of monomers to be added per $\mathrm{nm}^{2}$ of effective NP surface. $\mathrm{N}_{\mathrm{A}}$ is the Avogadro constant.

\section{Conversion of gold nanorods' molar concentration to mass concentration}

To convert the molar values of gold nanorods determined by UV/vis spectroscopy (cf.section 2.2, Eq. 1) into mass concentrations $[\mu \mathrm{g} / \mathrm{mL}]$, the molecular weight for each NPs was calculated based on the volume equation of a rod (Eq. S4).

$$
V_{N P}=\pi \times\left(\frac{\mathrm{d}_{\mathrm{c}}}{2}\right)^{2} \times d_{L}
$$

The nanorods molecular weight $\left(\mathrm{M}_{\mathrm{w}}\right)$ was calculated by following Formula S5: 


$$
M_{w}=V_{N P} \times \rho_{\text {gold }} \times N_{A}
$$

Where $\mathrm{p}$ is the gold density and $\mathrm{N}_{\mathrm{A}}$ is the Avogadro number.

With neglecting the contribution of the polymer coating to the mass of the NPs, ${ }^{\text {ii }}$ The conversion of mol to mass can be caculated by using the following Formula S6:

$$
\left(\frac{\mathrm{m}_{\mathrm{NP}}}{\mathrm{V}}\right)=\left(\mathrm{C} \times \mathrm{M}_{\mathrm{W}}\right)
$$

Where $\mathrm{C}$ is the concentration $[\mathrm{M}], \mathrm{m}$ is the mass $[\mathrm{mg}], \mathrm{M}_{\mathrm{w}}$ is the molecular weight $[\mathrm{g} / \mathrm{mol}]$ and $\mathrm{V}$, the volume of the NPs solution [mL].

\section{References}

${ }^{\text {i }}$ Pellegrino, T.; Manna, L.; Kudera, S.; Liedl, T.; Koktysh, D.; Rogach, A. L.; Keller, S.; Rädler, J.; Natile, G.; Parak, W. J., Hydrophobic Nanocrystals Coated with an Amphiphilic Polymer Shell: A General Route to Water Soluble Nanocrystals. Nano Letters 2004, 4, (4), 703- 707.

ii Rivera Gil, P.; Jimenez de Aberasturi, D.; Wulf, V.; Pelaz, B.; del Pino, P.; Zhao, Y.; de la Fuente, J.; Ruiz de Larramendi, I.; Rojo, T.; Liang, X.-J.; Parak, W. J., The Challenge to Relate the Physicochemical Properties of Colloidal Nanoparticles to Their Cytotoxicity. Acc. Chem. Res. 2013, 46, (3), 743-749. 